May 2016

"Sentiments in SVARs"

Patrick Fève and Alain Guay 


\title{
Sentiments in SVARs
}

\author{
Patrick Fève* \\ Toulouse School of Economics, University of Toulouse-Capitole (IDEI, IUF)
}

\author{
Alain Guay \\ Université du Québec à Montréal, CIRPÉE and CIREQ
}

May, 2016

\begin{abstract}
This paper investigates the contribution of sentiments shocks to US fluctuations in a Structural VAR setup with long, medium and short run restrictions. Sentiments shocks are identified as shocks orthogonal to fundamentals that accounts for most of the variance of confidence. We assess our identification procedure from simulation experiments and show that it performs pretty well. From actual data, we obtain that, contrary to news shocks on total factor productivity, sentiments shocks explain very little of quantities and prices. Sentiments shocks mostly appear as an idiosyncratic component of confidence. These results are robust to various perturbations of the benchmark model.
\end{abstract}

Keywords: Sentiment Shocks, News Shocks, SVARs, Identifying Restrictions

JEL Class.: C32, E32

*Address: Toulouse School of Economics, University of Toulouse-Capitole, manufacture des Tabacs, bât. F, 21 allée de Brienne, 31000 Toulouse, France. emails: patrick. feve@tse-fr.eu and guay . alain@uqam. ca. We would like to thank P. Beaudry, F. Canova, F. Collard, M. Dupaigne, J. La'o, M. Pientrunti, F. Portier, G. Primiceri and D. Stevanovic for valuable remarks, and participants in several conferences and seminars for helpful comments. We thank L. Savoie-Chabot for excellent research assistance. The traditional disclaimer applies. 


\section{Introduction}

Following the recent crisis, there has been a renewed interest in the identification of the sources of business cycles. A particular attention has been paid to the driving role of expectations. The literature has pointed out that changes in expectations may account for a bulk of aggregate fluctuations. ${ }^{1}$ First, multiple equilibria and sunspots fluctuations provide an explanation for expectations-driven business cycle (see Benhabib, Wang and Wen, 2015 and Farmer, 2012). ${ }^{2}$ Second, changes in expectations can result from news on economic fundamentals, such as technology improvement or economic policy (see Beaudry and Portier 2006, 2014, Jaimovich and Rebelo, 2009, Schmitt-Grohé and Uribe, 2012). Business cycles could be driven by anticipated change in future economic conditions which almost never actually materialize. Third, shifts in market sentiments can appear without any modification in economic outcomes (see e.g. Lorenzoni, 2009, Forni, Gambetti, Lippi, and Sala, 2013). These sentiments shocks originate from information frictions and can capture waves of optimism and pessimism disconnected from any changes in economic fundamentals (see Angeletos and La'o, 2013 and Angeletos, Collard and Dellas, 2014).

There does not exist a consensus about the contribution of news and sentiments shocks to aggregate fluctuations. Using Structural VectorAutoregressions (SVARs) with long-run and short-run restrictions, Beaudry and Portier (2006) find that news shocks on Total Factor Productivity (TFP) account for more than a half of output fluctuations. ${ }^{3}$ They also obtain similar findings for consumption, investment and hours (see Beaudry and Portier, 2014). However, Barsky and Sims (2011), using the SVARs setup with another identification strategy, show that news shocks on TFP account for a sizeable fraction of output fluctuations but contribute modestly to recessions. ${ }^{4}$ Forni, Gambetti, and Sala (2014) consider a VAR model augmented with factors and obtain that the impulse responses for news shock do not generate business type fluctuations. In addition, Forni, Gambetti, Lippi and Sala (2013) find that noise shocks, unrelated to economic fundamentals, entail long lasting responses of output, consumption and investment and represent a third of their variance. Using a Dynamic Stochastic General Equilibrium (DSGE) model, Blanchard, L'Huillier and Lorenzoni (2013) obtains

\footnotetext{
${ }^{1}$ The papers of Blanchard (1993), Hall (1993) and Cochrane (1994) has already highlighted the role of consumer expectations in business cycle analysis.

${ }^{2}$ We do not forget the seminal contributions (among others) in macroeconomics of Benhabib and Farmer (1994) and Farmer (1999).

${ }^{3}$ The paper of Cochrane (1994) was the first to investigate the role of news shock in a bivariate consumption and income SVAR setup, but Beaudry and Portier (2006) were the first to characterize news shock on TFP and its dynamic effects.

${ }^{4}$ Another part of the controversy concerns the response of investment. In Beaudry and Portier (2006), investment immediately jumps, whereas it decreases on impact in Barsky and Sims (2011).
} 
that the noise shock accounts for the bulk of output fluctuations at a yearly horizon. This is in contrast with Barsky and Sims (2012) who find from the estimation of a structural model that news shock is the main contributor to aggregate fluctuations, leaving a minor role to noise and sunspot shocks. Angeletos, Collard and Dellas (2014) obtain from various estimated DSGE models that confidence shock, unrelated to any fundamentals, can explain about one half of output volatility at business-cycle frequencies (6-32 quarters).

The heterogeneity of the quantitative findings partly results from the use of different structural models (the parametric structure of the DSGE model deeply impacts the reduced form) and methods (restrictions in SVARs) imposed for identification. Regarding these conflictual results, we propose a simple and weakly restrictive identification scheme of the sentiments shocks as well as other structural shocks in a SVAR setup. SVARs has been widely used for identification of structural shocks and their dynamic effects. ${ }^{5}$ The literature offers many examples of the relevance of the SVAR approach for macroeconomic modeling purposes (see Christiano, Eichenbaum and Evans, 2005). ${ }^{6}$ Their ability to properly uncover structural shocks and their contribution to the business cycle is still subject to controversy ${ }^{7}$ but continuous and significant improvements of this setup enhance the usefulness of this tool for developing business cycle theories. ${ }^{8}$

A key variable in our quantitative analysis is the sentiments shock. The sentiments shock is identified as a shock $i$ ) orthogonal to fundamentals (for example expected and unexpected or surprise TFP shocks) ii) with no long-run effect on TFP and other real quantities (per capita output, consumption or investment) and iii) that accounts for most of the variance of (either consumer or Chief Executive Officer, CEO) confidence for a given horizon. Restrictions $i$ ) and ii) are very standard in the SVAR literature, as they just exploit long-run restrictions and the exogeneity of a proper measure of TFP. The novelty here concerns the restriction $\mathrm{iii}$ ). The sentiments shock is identified as a transitory shock that best explains future movements in the measure of confidence up to a certain horizon. This restriction is in accordance with Angeletos, Collard and Dellas (2014), who obtain that the estimated confidence from various DGSE models is highly correlated with the University of Michigan Index of Consumer Sentiment.

We also use different restrictions to identify other (fundamental) shocks: an unexpected (or sur-

\footnotetext{
${ }^{5}$ This includes the dynamic effects of monetary policy, government spending, technology and news shocks.

${ }^{6}$ The news shock approach is a recent illustration of the relevance of SVARs for the development of business cycle theories (see Beaudry and Portier, 2006 and Jaimovich and Rebelo, 2009).

${ }^{7}$ One of the well known examples is the identification of permanent technology shocks, but we better know under which conditions SVARs may properly identify these shocks (see Chaudourne, Fève and Guay, 2014, for a review).

${ }^{8} \mathrm{~A}$ recent good example is the extension to Factor Augmented VARs with news shock to deal with non-invertibility problems. We will examine this quantitative issue.
} 
prise) shock on TFP and a news shock on TFP. Unexpected and news shocks on TFP are identified using both long-run and short-run restrictions (see Blanchard and Quah, 1989, and Beaudry and Portier, 2006). The remaining temporary shock is directly deduced from the identification of sentiments shock. Armed with these identified shocks, we can investigate which ones drive the business cycle. In addition, we can determine the relative contribution of fundamental and non-fundamental shocks to our measure of confidence.

The existing literature offers two representations of confidence/sentiments in unique-equilibrium, rational-expectations models. Following Angeletos and La'o (2013), Angeletos, Collard and Dellas (2014) propose a tractable representation of information frictions in DSGE models and the confidence shock appears as an additional exogenous state variable in the state-space representation of the economy. Barsky and Sims (2012), Blanchard, L'Huillier and Lorenzoni (2013), Forni, Gambetti, Lippi and Sala (2013) consider the information imperfection under the form of a noisy signal about technology. In this setup, sentiments are (partially) linked to the signal that the agents receive. Our approach remains agnostic about which type of representation is the more relevant but can potentially capture the dynamic impact of sentiments shocks on prices and quantities from both sources. Our goal is to properly identify and quantify the contribution of sentiments shocks to the business cycle and which type of shocks influence the confidence.

To assess the reliability of our identification procedure, we simulate a DSGE model (see Ireland, 2003) with nominal frictions, permanent technology shocks (unexpected and expected), persistent demand (monetary policy) shocks and shocks to confidence. We investigate two polar cases. In the first case, we simulate an economy in which sentiments shocks are idiosyncratic to confidence and have no aggregate effects. In the second case, we consider an economy in which agents receive a noisy signal about future improvement in TFP (noisy news). This signal also affect the confidence, so news and noise on TFP equally explain confidence. This second case is particularly challenging for SVARs because noises imply non-identifiability of the shocks (See Barsky and Sims, 2012, Blanchard, L'Huillier and Lorenzoni, 2013 , Forni, Gambetti, Lippi and Sala, 2013), i.e. agents (and thus the econometrician) can not disentangle the fundamental (news) shock from the noise on impact. ${ }^{9}$ Our simulation experiments show that our approach works very well in the first situation of idiosyncratic sentiments, but it still deliver reliable results in the presence of noises, despite the fact that the

\footnotetext{
${ }^{9}$ The other representation of confidence (Angeletos and La'o, 2013 and Angeletos, Collard and H. Dellas, 2014) does not imply the same problems about non-identifiability and involves no additional difficulties for the SVARs approach. The reason is that the information problem just appears under the form of an additional exogenous state variable.
} 
noisy signal is the main driver of output fluctuations in the DSGE model. ${ }^{10}$ In these experiments, we maintain that the monetary policy shock has no effect on sentiments. We relax this assumption and we investigate the case when news, demand and sentiments shocks equally explain confidence. In this case, the contribution of the demand shocks to the business cycle will be wrongly attributed to the sentiments shocks leading to an overestimation of the contribution of sentiments shocks to the business cycle.

We next apply our SVAR setup to the US economy for the sample period 1960:1-2011:4. From the dynamic responses to the four identified shocks and variance decompositions, our five main results are the following. First, sentiments shock explains very little of output and inflation. Second, the news and sentiments shocks equally contribute to consumer (and business sector) confidence. Third, the news shock on TFP accounts for most of the variance of GDP, except in the short-run. Fourth, the remaining transitory shock ${ }^{11}$ represents a non-negligible fraction of output variance in the short-run. Fifth, news on TFP and the remaining stationary shock are almost the sole drivers of inflation.

The presence of news shocks challenges the identification of structural perturbations from SVARs, as this expected shock could imply non-fundamental representations. Using the simple procedure proposed by Forni and Gambetti (2014), we assess this issue by conducting orthogonality tests and considering a Factor Augmented VECM. ${ }^{12}$ Our findings suggest that, whereas factors are not orthogonal to the identified news shock, non-fundamentalness does not matter quantitatively and all our results obtained from the benchmark case are valid. These above results are also very robust to various other perturbations of the benchmark model (alternative measures of quantities, inflation and confidence; alternative identification strategy). Our findings are in line with Beaudry and Portier (2006) and Barsky and Sims (2012). News shocks on TFP are an important driver of the business cycle and sentiments shock appears to be mostly as an idiosyncratic component of confidence.

The paper is partly built from the existing literature. First, our approach decomposes the sources of business cycles into permanent and transitory components (supply shocks versus demand shocks) and thus follows the approach initiated by Shapiro and Watson (1988), Blanchard and Quah (1989) and Galí (1999). However, we disentangle two permanent shocks and two transitory shocks, i.e. shocks

\footnotetext{
${ }^{10}$ In our simulation experiments, the noisy signal explains almost $70 \%$ of output fluctuations.

${ }^{11}$ In the empirical section of the paper, we decide to label this shock as a demand shock, because it persistently increases both prices and quantities.

${ }^{12}$ This procedure can detect one kind of non-fundamentalness, i.e., the one that arises when the econometrician's information set is smaller than that of agents.This differs from the other kind of non-fundamentalness problem originating from imperfect information with respect to agents' information set. A part of the simulation experiments in Section 2 is devoted to examine the quantitative severity of this latter source of non-fundamentalness. For a discussion on nonfundamental representations and the difference with a non-invertible representation, see Gouriéroux and Monfort (2015), p. 7-8.
} 
that are absent from these celebrated papers. Second, our empirical strategy combines the identification scheme previously proposed by Beaudry and Portier (2006) and Barsky and Sims (2011), but we do not focus on news shock only and its contribution to the business cycle. Finally, Matsusaka and Sbordone (1995) have been the first (to our knowledge) to consider the role played by confidence in SVARs and the associated sentiments shocks on key aggregate variables. However, they only use a partial identification of shocks in their structural autoregressions ${ }^{13}$ and do not consider other potential competing sources of aggregate fluctuations.

The paper is organized as follows. In the first section, we present the SVAR setup and our identification strategy. In section 2, we assess the reliability of our strategy. Section 3 reports the main empirical results. Section 4 is devoted to the robustness analysis. A last section concludes.

\section{Identification from SVARs}

Our empirical strategy relies on SVARs with both long-run, medium-run and short-run restrictions. More precisely, we develop a Structural Vector Error Correction Model (SVECM) which allows to impose long-run restrictions compatible with cointegration relationships among non-stationary variables. ${ }^{14}$ We next impose a set of minimal restrictions on the medium-run and short-run dynamics. Let $y_{t}$ be a vector that includes four time series variables

$$
y_{t}=\left(\begin{array}{c}
\mathrm{TFP}_{t} \\
\text { Quantities }_{t} \\
\text { Inflation }_{t} \\
\text { Confidence }_{t}
\end{array}\right) \text {. }
$$

The variable $\mathrm{TFP}_{t}$ is a measure of Total Factor Productivity. This variable is used here for the separate

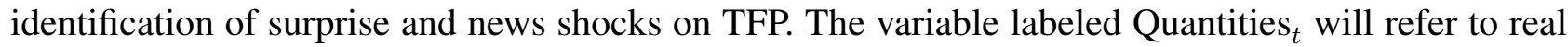
non-stationary variables (GDP, consumption, investment, labor productivity). The variable Inflation ${ }_{t}$ is introduced for identification of transitory shocks. Finally, Confidence $t_{t}$ is a measure of confidence in the private sector (households and business sector). This variable is central in our quantitative analysis. It allows to identify the sentiments shock, but we also use it to evaluate the contribution of

\footnotetext{
${ }^{13}$ They impose a recursive representation of the VAR system, without a full characterization of shocks. This is typically the SVAR representation used in Barsky and Sims (2012), but as they judiciously noticed, this setup is just an auxiliary model without any a priori structural economic interpretation. Their structural DSGE model is then estimated by indirect inference from this auxiliary SVAR.

${ }^{14}$ We relax this SVECM representation in section 4.3 by considering a level specification of the variables.
} 
various structural shocks to confidence. We shall describe these variables in more details below. This set of variables is assumed to follow a Vector Error Correction Model (VECM) of the form ${ }^{15}$

$$
\Delta y_{t}=\alpha \beta^{\prime} y_{t-1}+\Gamma_{1} \Delta y_{t-1}+\ldots+\Gamma_{p} \Delta y_{t-p}+u_{t}
$$

where $\Delta$ is the first difference operator and $p$ denotes the number of selected lags on $\Delta y_{t}$. $\alpha$ and $\beta$ are $K \times r$ (where $K=4$ ) matrices of loading parameters and cointegrating vectors, respectively. The $(K \times K)$ matrices $\Gamma_{j}(j=1, \ldots, p)$ are referred to short-run parameters. The deterministic part is omitted to simplify the presentation without altering the results below. Finally, the error term $u_{t}$ is assumed to be a zero-mean weak white noise with a time invariant covariance matrix, $E\left(u_{t} u_{t}^{\prime}\right)=\Sigma$. From the VECM (1), the Moving-Average representation is uncovered, namely:

$$
\Delta y_{t}=C(L) u_{t}
$$

with $C(L)=\sum_{i=0}^{\infty} C_{i} L^{i}$ and $C_{0}=I_{K}$.

The reduced form error terms in $u_{t}$ are a combination of structural shocks $\varepsilon_{t}$. A common normalization identification assumption is that the structural innovations $\varepsilon_{t}$ have zero-mean and identity covariance matrix. In addition, they are linearly related to $u_{t}$ such that

$$
u_{t}=A_{0} \varepsilon_{t}
$$

where $A_{0}$ is $K \times K$ matrix. From the above normalization, it follows that $\Sigma=A_{0} A_{0}^{\prime}$. Without additional restrictions, $A_{0}$ is not uniquely identified and we must impose additional restrictions. Following Lütkepohl (2007), the multivariate Beveridge-Nelson Moving-Average representation of the VECM (1) can be obtained by applying the Granger's representation theorem, namely

$$
y_{t}=C(1) \sum_{i=1}^{t} u_{i}+\sum_{i=0}^{\infty} C_{i}^{*} u_{t-i}+y_{0}^{*}
$$

where $y_{0}^{*}$ contains the initial values and $C_{i}^{*}$ are absolutely summable. The $(K \times K)$ matrix $C(1)$ allows to uncover the long-run effect of structural shocks and it is given by

$$
C(1)=\beta_{\perp}\left[\alpha_{\perp}^{\prime}\left(I_{K}-\sum_{i=1}^{p} \Gamma_{i}\right) \beta_{\perp}\right]^{-1} \alpha_{\perp}^{\prime},
$$

\footnotetext{
${ }^{15}$ We also consider a level representation of variables in the robustness analysis. See section 4.3
} 
where $\alpha_{\perp}$ and $\beta_{\perp}$ denote the orthogonal complements of $\alpha$ and $\beta$. The rank of the long-run matrix $C(1)$ is $K-r$, where $r$ is the cointegrating rank. Thus, there exists $K-r$ common trends in the terminology of Stock and Watson (1988). Using (2) and (3), the long-run effects of the structural shocks is then given by $C(1) A_{0}$. Because the matrix $A_{0}$ is of full rank, the rank of $C(1) A_{0}$ is $K-r$ and there can be at most $r$ zero columns in the matrix of the long-run effects of the structural shocks. It means that at most $r$ structural shocks can have transitory effects and at least $K-r$ structural shocks can have permanent effects. Consequently, the rank of $C(1) A_{0}$ yields at most $r(K-r)$ independent restrictions. The knowledge of the cointegrating rank $r$ gives the maximum number of independent restrictions that can be imposed on the long-run effects of the structural shocks (see Lütkepohl, 2007). However, the number of transitory shocks can be smaller that $r$ requiring that the remaining structural permanent shocks are linearly dependent in order to respect the rank condition for $C(1) A_{0}$. For the local identification of the structural shocks, we must impose $K(K-1) / 2$ restrictions on $A_{0}$ and $C(1) A_{0}$. With $K=4$, six restrictions (at least) are needed to identify the four structural shocks.

The aim of the identification strategy is to retrieve two potential permanent structural shocks, labeled as a pure surprise TFP shock (or unexpected TFP shock) and a news TFP shock (a shock that does not materialize today but that can follow a slow diffusion process), and two transitory shocks, one of them being the sentiments shock. The first restriction (Identification I) aims to disentangle the permanent and the transitory shocks. It uses the empirical result (see below) that we cannot reject the hypothesis the rank of $C(1) A_{0}$ is equal to one.

Identification I (two long-run restrictions): the two stationary shocks (including sentiments) have no long-run effect on TFP and quantities.

This restriction, together with the cointegration between TFP and quantities, allows to identify separately the two supply and demand shocks. This implies that the matrix of long-run multiplier $A(1)=C(1) A_{0}$ is given by

$$
A(1)=\left[\begin{array}{cccc}
a_{11}(1) & a_{12}(1) & 0 & 0 \\
\tilde{a}_{11}(1) & \tilde{a}_{12}(1) & 0 & 0 \\
0 & 0 & 0 & 0 \\
0 & 0 & 0 & 0
\end{array}\right]
$$

where $a_{11}(1)=\beta_{12} \tilde{a}_{11}(1)$ and $a_{12}=\beta_{12} \tilde{a}_{12}(1)$. $\beta_{12}$ denotes the cointegrating parameter between TFP and quantities. This structure of the matrix $A(1)$ is a direct consequence of the long-run restriction 
that we impose. It exists one common long-run trend in the vector of variables $y_{t}$, the share of the variance of TFP and quantities explained by the two supply shocks are the same (the first and second lines are perfectly co-linear) and the two stationary shocks have no long-run effect on TFP and quantities. This is compatible with a rank of the long-run matrix $A(1)$ equal to one, i.e. one common trend. The two supply shocks have a proportional effect on the first two variables and the two other shocks are transitory in respect with these two non-stationary variables. This means that the number of zeros in the matrix $A(1)$ and the rank of $A(1)$ result in two identifying restrictions only. This leaves to consider four additional restrictions to properly identify the four structural shocks.

Identification II (one short-run restriction): the news TFP shock has no short-run effect on the level of TFP.

This short-run restriction follows the empirical strategy first proposed by Beaudry and Portier (2006). This assumption is now common in the SVAR literature to disentangle a pure surprise TFP shock from a news shock (see Beaudry and Portier, 2005, 2006, Barsky and Sims, 2011, Beaudry and Lucke, 2010). ${ }^{16}$ A news shock accounts for expectations of future productivity changes and it is orthogonal to a surprise TFP shock. Namely, a news shock has zero impact effect on the level of TFP but could explain the main bulk of TFP in the medium and the long-run.

Identification III (two short-run restrictions): the two stationary shocks (including sentiments) have no short-run effect on the level of TFP.

This restriction also implies that the measure of TFP is unaffected on impact by the two stationary shocks. The sentiments shock represents shifts in expectations about business cycles without changes in the fundamentals of the economy. The zero impact effect of the sentiments shock is a weak version of the fact that this shock is assumed to be disconnected from changes in economic fundamentals and, in particular, changes in aggregate productivity. This identification also imposes that the remaining stationary shock has no contemporaneous impact on TFP. If the TFP is properly measured (see Fernald 2012), we can expect almost no effect of stationary shocks on TFP. This restriction combined with identification II allows to identify the structural technology shock to be the unpredictable residual component of TFP. ${ }^{17}$

\footnotetext{
${ }^{16}$ This also corresponds to the specification of news shocks in DSGE models (see Schmitt-Grohé and Uribe, 2012, Fujiwara, Hirose and Shintani, 2011, and Khan and Tsoukalas, 2012).

${ }^{17}$ We will discuss this identification in the robustness analysis.
} 
Identification IV (one medium-short-run restriction): among transitory shocks, the sentiments shock maximizes its contribution to the variance decomposition of confidence series up to a certain horizon.

The sentiments shock is identified as the shock that best explains the future movements in the measure of (consumer or business sector) confidence conditional on the identification of the supply shocks (the two permanent shocks in our setup). In other words, identification IV imposes that the sentiments shock is the shock that represents the largest share of the confidence's variance (up to a certain horizon) among the two transitory shocks conditional on identification I and identification II of the TFP and news shocks. This identification strategy maximizes the importance of the sentiments shock as an explanation of the fluctuations in the private confidence.

This identifying restriction deserves here two comments. First, this identification is consistent with previous findings. Angeletos, Collard and Dellas (2014) find that the estimated confidence from various DGSE models is highly correlated with the University of Michigan Index of Consumer Sentiment and the Conference Board's Indices of Consumer or Producer Confidence. Second, this identification yields an upper bound estimate on the effects of sentiments shocks. To see this, suppose that the remaining stationary shock is main driver of confidence. In such a case, the contribution of these shocks to the business cycle will be attributed to the sentiments shocks. ${ }^{18}$ We will now expound the implementation of this procedure.

\section{Implementation}

The identification of sentiments shocks is achieved by implementing the following two-step procedure.

Step 1: The first step uses identification I and identification II to uncover the two potential permanent shocks, i.e., the unanticipated and the anticipated technology shocks. This allows us to identify the two first columns of the $A_{0}$ matrix. We implement this first step by imposing that the contemporaneous effect of the remaining stationary shock to confidence is set to $\bar{a}_{0,43}$, i.e., an initial value in the procedure that can be either zero or any other. This implies the following organization of the matrix

\footnotetext{
${ }^{18}$ See the simulation experiments in the next section for an illustration.
} 
$\tilde{A}_{0}$

$$
\tilde{A}_{0}=\left[\begin{array}{cccc}
a_{0,11} & 0 & 0 & 0 \\
a_{0,21} & a_{0,22} & a_{0,23} & a_{0,24} \\
a_{0,31} & a_{0,32} & a_{0,33} & a_{0,34} \\
a_{0,41} & a_{0,42} & \bar{a}_{0,43} & a_{0,44}
\end{array}\right] .
$$

So, conditional on the identification of supply shocks, the matrix $\tilde{A}_{0}$ is then just-identified.

Consider now the forecast error of $\Delta y_{t}$ function from this identification schema. The $\mathrm{k}-$ step ahead forecast error is then given by

$$
\Delta y_{t+k}-E_{t} \Delta y_{t+k}=\sum_{\tau=0}^{h} C_{\tau} A_{0} \varepsilon_{t+k-\tau}=\sum_{i=0}^{h} C_{\tau} \tilde{A}_{0} F \varepsilon_{t+k-\tau}
$$

for all $F$ such that $F F^{\prime}=I$ and $h=k-1$. The matrix $F$ is an orthonormal matrix and $A_{0}=\tilde{A}_{0} F$. Now consider that $F$ has the following structure

$$
F=\left[\begin{array}{ll}
I_{2} & \mathbf{0}_{2} \\
\mathbf{0}_{2} & F_{22}
\end{array}\right]
$$

where $I_{2}$ is an identity matrix of dimension $2 \times 2, \mathbf{0}_{\mathbf{2}}$ a matrix of dimension $2 \times 2$ containing only zero as elements and $F_{22}$ is a $2 \times 2$ orthonormal matrix such that $F_{22} F_{22}^{\prime}=I_{2}$. Consequently, the first two columns of $A_{0}$ and $\tilde{A}_{0} F$ are the same. These two first columns identify the impact of both supply shocks (unexpected and news shocks on TFP) on the four variables contained in $y_{t}$. The first two columns of the matrix $A_{0}$ are then identified. Consider the following partition $A_{0}=\left[\begin{array}{ll}A_{1} & A_{2}\end{array}\right]$, where the matrix $A_{2}$ is of dimension $4 \times 2$. We identify the last two columns of $A_{0}$ by finding a matrix $F_{22}$ with $F_{22} F_{22}^{\prime}=I$ such that $A_{2}=\tilde{A}_{2} F_{22}$ for all admissible matrices $F_{22}$ and where the matrix $\tilde{A}_{2}$ contains the last two columns of $\tilde{A}_{0}$. The resulting moving-average component

$$
\sum_{\tau=0}^{h} C_{i} \tilde{A}_{2} F_{22} \varepsilon_{t+h-\tau}^{T}=\sum_{\tau=0}^{h} C_{i} A_{2} \varepsilon_{t+h-\tau}^{T}
$$

gives the forecast error of all variables contained in $y_{t}$ as function of the transitory shocks only $\varepsilon_{t}^{T}$ with $\varepsilon_{t}=\left(\varepsilon_{t}^{P^{\prime}}, \varepsilon_{t}^{T^{\prime}}\right)^{\prime}$ and $\varepsilon_{t}^{P}$ is the vector of the permanent structural shocks. Accordingly, the share 
of the forecast error of the variable $i$ to the transitory shock $j$ at horizon $h$ is:

$$
\begin{aligned}
\Omega_{i, j}(h) & =\frac{\sum_{\tau=0}^{h} C_{i, \tau} \tilde{A}_{2} F_{22} e_{j} e_{j}^{\prime} F_{22}^{\prime} \tilde{A}_{2}^{\prime} C_{i, \tau}^{\prime}}{\sum_{\tau=0}^{h} C_{i, \tau} \Sigma C_{i, \tau}^{\prime}} \\
& =\frac{\sum_{\tau=0}^{h} C_{i, \tau} \tilde{A}_{2} \gamma \gamma^{\prime} \tilde{A}_{2}^{\prime} C_{i, \tau}^{\prime}}{\sum_{\tau=0}^{h} C_{i, \tau} \Sigma C_{i, \tau}^{\prime}} .
\end{aligned}
$$

where $e_{j}$ is a selection $2 \times 1$ vector with one in the $j$ th element and zeros elsewhere and $\gamma$ is the $j$ th column of $F_{22}$. Given this computed share of forecast error due to transitory shocks, we now turn on the second step that allows to identify the sentiments shock.

Step 2: We choose the impulse vector that maximizes the cumulative sum corresponding to the contribution of the sentiments shock to the forecast error variance of confidence up to horizon $H$ given by: ${ }^{19}$

$$
\gamma^{*}=\operatorname{argmax}_{\gamma} \sum_{h=0}^{H} \Omega_{4,4}(h)
$$

subject to

$$
\left\{\begin{array}{l}
\tilde{A}_{2}(1,1)=0 \\
\tilde{A}_{2}(1,2)=0 \\
\gamma^{\prime} \gamma=1
\end{array}\right.
$$

This maximization problem chooses the sub-matrix $A_{2}$ maximizing contributions to $\sum_{h=0}^{H} \Omega_{4,4}(h)$. The constraint $\tilde{A}_{2}(1,1)=\tilde{A}_{2}(1,2)=0$ imposes that the stationary shocks have no contemporaneous impact on TFP. Uhlig (2003) shows that this maximization problem can be rewritten as a quadratic form in which the non-zero portion of is $\gamma$ the eigenvector associated with the maximum eigenvalue of a weighted sum of $\left(C_{4, \tau} \tilde{A}_{2}\right)^{\prime}\left(C_{4, \tau} \tilde{A}_{2}\right)$ over $\tau$ (see also Barsky and Sims, 2011). In other words, this procedure essentially identifies sentiments shock as the main driver of the cumulative sum of the confidence variance decomposition (up to the horizon $H$ ) conditional on the identification of supply shocks in the the first step (see Identification I and Identification II).

\section{Summing-up}

\footnotetext{
${ }^{19}$ Francis, Owyang, Roush and DiCecio (2012) propose to use the forecast error variance for a horizon $h$ given by $\Omega_{i, j}(h)$ instead of its cumulative sum.
} 
To sum-up, our restrictions imply the followings in the short-run: $i$ ) the measure of TFP is unaffected by news and stationary shocks on impact; $i$ ) quantities, inflation and confidence can freely respond to each shock in the short-run and iii) among shocks with non-permanent effects, the sentiments shock is the main driver of confidence in the short-medium-run. According to Identifications $\mathrm{I}-\mathrm{IV}$, the matrix of impact responses $A_{0}$ is organized as follows:

$$
A_{0}=\left[\begin{array}{cccc}
a_{0,11} & 0 & 0 & 0 \\
a_{0,21} & a_{0,22} & a_{0,23} & a_{0,24} \\
a_{0,31} & a_{0,32} & a_{0,33} & a_{0,34} \\
a_{0,41} & a_{0,42} & a_{0,43} & a_{0,44}
\end{array}\right]
$$

Three lines are of particular interest for our quantitative anlysis: $\left\{a_{0,2 i}, a_{0,3 i}, a_{0,4 i}\right\}$ with $i=1,2,3,4$ in the $A_{0}$ matrix. These lines yield the short-run responses of quantities, prices and confidence to identified shocks. Note that we impose no restriction on these lines except that $a_{0,43}$ is obtained from our identification scheme that the sentiments shock is the main driver of confidence, i.e. it is obtained from the maximization problem (4). Most of the restrictions concerns the first line, associated to the response of TFP to the four shocks. So, the measure of TFP is mainly used for identification purpose.

\section{Assessing the SVAR Model}

We use artificial data generated from a DSGE model to assess the performance of our identification strategy. We investigate here two polar cases. In the first case, we simulate an economy in which sentiments shocks are idiosyncratic to confidence and have no aggregate effects. In the second case, we consider an economy in which agents receive a noisy signal about future improvement in TFP ("noisy news"). The model used is similar to Ireland (2003) extended to the case of sentiments. ${ }^{20}$ The model features monopolistic competition and nominal price rigidities under the form of a quadratic adjustment costs function. The economy is composed of a representative household, a representative finished goods-producing firm, a continuum of intermediate goods-producing firms and a central bank. The model is feeded by a permanent TFP shock, with both an unexpected and expected (with one lag) component. The model also includes persistent shocks to the monetary policy. The only difference with Ireland (2003) concerns the presence of a variable related to confidence. More precisely,

\footnotetext{
${ }^{20}$ To save space, we do not report the description of the model and we refer to Ireland (2003).
} 
we introduce the following measurement equation for confidence:

Confidence $_{t}=\rho_{s}$ Confidence $_{t-1}+\mu_{1} \varepsilon_{t}^{\text {unexpected }}+\mu_{2} \varepsilon_{t}^{\text {news }}+\mu_{3} \varepsilon_{t}^{\text {noisy news }}+\mu_{4} \varepsilon_{t}^{\text {monetary }}+\mu_{5} \varepsilon_{t}^{\text {idiosyncratic }}$, where $\varepsilon_{t}^{\text {unexpected }}, \varepsilon_{t}^{\text {news }}, \varepsilon_{t}^{\text {noisy news }}, \varepsilon_{t}^{\text {monetary }}$ and $\varepsilon_{t}^{\text {idiosyncratic }}$ are the the surprise TFP shock, the news TFP shock, the noise shock (on expected TFP), the monetary policy shock and an idiosyncratic component of confidence, respectively.

This specification is similar (to some respects) to the one adopted by Barsky and Sims (2012). It allows for an uniform persistence effect of various shocks to confidence as it includes an autoregressive parameter $\rho_{s} \in[0,1)$. In practise we set $\rho_{s}=0.8$. The effect of various sources of fluctuations in confidence are governed by the parameters $\mu_{i}(i=1, . ., 5)$. In what follows, we set $\mu_{1}=0$, i.e. unexpected TFP shock are constrained to have no effect on confidence. ${ }^{21}$ We concentrate our quantitative experiments to the four parameters $\mu_{i}(i=2, \ldots 5)$. The parameters $\mu_{2}$ and $\mu_{4}$ govern the contribution of news TFP shock and monetary (demand) shock on the confidence. These two fundamental shocks of the model may thus affect confidence. In our benchmark quantitative evaluation we set $\mu_{4}=0$, so fundamental demand shocks have no effect on confidence. Because our identification strategy, i.e. among transitory shocks, the shock that contributes much to fluctuations in confidence is not a demand shock, we will relax this assumption and inspect how our identification procedure still works well.

Two parameters will also receive a particular attention. First, the parameter $\mu_{5}$ governs the effect of an idiosyncratic shock to confidence. If $\mu_{3}=0$ (no effect of noise), the confidence variable is only explained (up to the news shock in TFP) by an idiosyncratic component that exerts no effect on aggregate variables (TFP, output, inflation, ...). In this case, the measurement equations rewrites

$$
\text { Confidence }_{t}=\rho_{s} \text { Confidence }_{t-1}+\mu_{2} \varepsilon_{t}^{\text {news }}+\mu_{5} \varepsilon_{t}^{\text {idiosyncratic }}
$$

This particular parametrization represents a situation where the sentiments shock (the idiosyncratic shocks in this case) only influences confidence, without any aggregate consequences. This is the first polar case examined. For the second polar case, the parameter $\mu_{3}$ measures the effect of noise on confidence. This noise comes from a noisy signal that agents receive about future improvement in TFP, i.e. "noisy news" (see the discussion below). We impose $\mu_{5}=0$, i.e. fluctuations in confidence

\footnotetext{
${ }^{21}$ In a sensitivity analysis, we explore the effects on non-zero effect of the unexpected TFP shock. Our main findings are left unaffected. To save space, we do not report the results.
} 
are now partly the consequence of shocks, unrelated to economic fundamentals that both affect prices, quantities and confidence. This shock is obtained by a standard signal extraction problem when private agents receive a noisy signal on news shocks on TFP. This means that we must include in the DSGE model an additional parameter (the variance of noise). In practise, we set the same variance for the news and the noise in TFP. In addition, consistent with the information problem, the parameters $\mu_{2}$ and $\mu_{3}$ are set to be equal in the confidence equation. So the measurement equation now takes the form:

$$
\text { Confidence }_{t}=\rho_{s} \text { Confidence }_{t-1}+\mu_{2} \underbrace{\left(\varepsilon_{t}^{\text {news }}+\varepsilon_{t}^{\text {noisy news }}\right)}_{\text {Noisy signal }} \text {. }
$$

For this case, sentiments shocks are assimilated to "noisy news" shock. To compute artificial timeseries, we draw 1000 independent random realizations of the TFP shocks (unexpected and expected), the monetary policy shock, and depending on the experiment on the idiosyncratic or the noise shock. Using the parameters of Table 1, we compute 1000 equilibrium paths for TFP, output, inflation and confidence. In all experiments, the sample size is equal to 250 quarters, as in actual data. In order to reduce the influence of initial conditions, the simulated sample includes 250 initial points which are subsequently discarded before the estimation of VECM. The number of lags in VECM models is set to 3, a value typically used in empirical studies. We apply the identification procedure described in Section 1 and we inspect if the SVAR model is able to uncover the true shocks. Each figure also report the $90 \%$ confidence interval (the grey area) together with the true response. We first start with the case of idiosyncratic shock on confidence, then consider the case of "noisy news" shocks on TFP and then discuss the reliability of our identification procedure when demand (monetary policy) shocks can affect confidence. ${ }^{22}$

\section{Idiosyncratic Shock on Confidence}

In this first experiment, only the news and the idiosyncratic shocks can affect confidence and sentiments shocks have no effect on economic activity. The results are reported in Figure 1 . The SVAR model reproduces very well the true responses of TFP, output, inflation and confidence for both shocks. The true responses are within the $90 \%$ confidence interval of the estimated ones. Notice that when we inspect the invertibility of the DSGE model (see Fernandez-Villaverde, Rubio-Ramirez,

\footnotetext{
${ }^{22}$ To avoid singularity problems in the case of noisy signal about expected TFP, we add a small measurement error in the sentiments/confidence equation. See Table 1.
} 
Sargent and Watson, 2007), we obtain that no eigenvalue exceeds unity, meaning the VAR setup is able to recover the structural shocks. This is also confirmed by the comparison of forecast error variance decompositions and the high correlation between the true and estimated structural shocks. For example, the DSGE model is calibrated such that the news and the idiosyncratic shocks equally explain the variance of confidence. In the SVAR model, the variance explained by news shocks is equal to $53 \%$ in the short run.

“Noisy news” Shock on TFP

We now examine another situation when agents receive a noisy signal about future improvement in TFP. The (log of) TFP is described by the following equation

$$
\operatorname{TFP}_{t}=\gamma_{z}+\operatorname{TFP}_{t-1}+\varepsilon_{t}^{\text {unexpected }}+\varepsilon_{t-1}^{\text {news }}
$$

Private agent receives a noisy signal $s_{t}$ about the news shock, i.e. $s_{t}=\varepsilon_{t}^{\text {news }}+\nu_{t}$, where the noise $\nu_{t}$ has zero mean and variance $\sigma_{\nu}^{2}$. The expected next period TFP is given by

$$
E\left(\mathrm{TFP}_{t+1} / \mathcal{I}_{t}\right)=\gamma_{z}+\mathrm{TFP}_{t}+E\left(\varepsilon_{t}^{\text {news }} / \mathcal{I}_{t}\right)
$$

where the information set $\mathcal{I}_{t}$ is given by present and past values of $\mathrm{TFP}_{t}$ and $s_{t}$. The term $E\left(\varepsilon_{t}^{\text {news }} / \mathcal{I}_{t}\right)$ is obtained as the linear projection of $\varepsilon_{t}^{\text {news }}$ on $s_{t}$, that is

$$
E\left(\varepsilon_{t}^{\text {news }} / \mathcal{I}_{t}\right)=\alpha s_{t}
$$

where $\alpha=\sigma_{\varepsilon^{\text {news }}}^{2} / \sigma_{s}^{2} \equiv \sigma_{\varepsilon^{\text {news }}}^{2} /\left(\sigma_{\varepsilon^{\text {news }}}^{2}+\sigma_{\nu}^{2}\right)$. The agents cannot identify separately the news and the noise. In this version of the DSGE model, the noise shock on TFP can affect aggregate variables independently from any changes in fundamental shocks. As pointed out by Blanchard, L'Hullier and Lorenzoni (2013), this setup is really challenging for SVARs as without the use of strong theoretical restrictions (estimating for example a DSGE model with information problems), it seems impossible to properly identify shocks. We acknowledge that our identification procedure may suffer from the "noisy news" setup ${ }^{23}$ but we want to quantitatively evaluate if it is a serious problem. ${ }^{24}$

This is because agents cannot separate the news and the noise shocks. By varying the variance

\footnotetext{
${ }^{23}$ To circumvent this problem, Forni, Gambetti, Lippi and Sala (2013) propose to use SVARs with dynamic rotations.

${ }^{24}$ Note that we can not apply the procedure described in Fernandez-Villaverde, Rubio-Ramirez, Sargent and Watson (2007), because the noise creates a singularity problem into the measurement equation. In their notations, the matrix $D$ is non-invertible.
} 
of noise (with respect to the variance of news), we can increase or decrease the information problem. In practise, we set the same variance for the news and the noise shocks. It follows that the news and the noise equally explain confidence. With our parametrization (See Table 1), the contribution of the noisy signal to output fluctuations is almost $70 \%$. Note that, contrary to the previous experiment, the sentiments shock (the noise) can affect economic fluctuations.

The results are reported in Figure 2. The dynamic responses after an unexpected TFP shock are well reproduced (see for example the responses of output and inflation). The SVAR models tends to underestimate the true response of the TFP to a news shock, but the estimated responses for output, inflation and confidence are close to the true ones. The SVAR tends also to underestimate the true response of output and inflation to a demand shock, but the true response lies within the $90 \%$ confidence interval. Finally, the SVAR model reproduces well the true response of output and inflation to a noise shock and slightly but not significantly underestimates the response of confidence to this shock.

\section{Larger Contribution of Demand Shocks to Confidence}

Our simulation experiments have shown (in two polar theoretical setups) that our estimated responses closely correspond to the true ones, even if the econometrician face identification problems. However, in all these experiments, we imposed that the demand shock has no effect on confidence. A natural additional investigation is about the reliability of the procedure when our identification assumption is not verified. We parameterize the measurement equation for confidence such that news, demand and sentiments shocks equally explain the variance of confidence. The dynamic responses are reported in Figure 3. The estimated responses to the unexpected and news shocks on TFP are close to the true ones. This is not surprising because these two shocks are separately identified (from demand and sentiments shocks) using long-run restrictions. The main differences concern the estimated effects of the sentiments and demand shocks. The procedure tends to confound (in the very short-run) these two shocks. For example, the estimated response of output and inflation to a sentiments shock is positive, as in the case of a demand shock. The inspection of the correlation between the true and estimated structural shock reveals a positive link between the estimated sentiments shock with the true demand (monetary policy) shock, revealing the confusion creating by the identification procedure. Finally, the estimated response of confidence to demand shock (as imposed by the identification procedure) is close to zero. This finding is not problematic for our findings from actual data. They just indicate that if demand shocks contribute a lot to confidence, the econometrician tends to attribute too much weight on sentiments shock. If she obtains very small effect of sentiments shocks 
on prices and quantities, this just reveals that she would not confound this shock with a demand shock.

\section{Empirical Results}

After a description of the data, this section presents the main results from our benchmark specification (IRFs, variance decomposition and history).

\subsection{US Data}

Our identification of the news shocks requires the observation of the $\mathrm{TFP}_{t}$ variable, which we will decompose into an unexpected (or surprise) component and a news shock. This implies that the empirical measure of productivity properly reflects the unobserved variations in inputs. Recently, Fernald (2012) proposed a quarterly frequency measure with adjustments for variations in factor utilizationlabor effort and the workweek of capital. According to specification (1), the growth rate of $\mathrm{TFP}_{t}$ is then included in our VECM. The variable Quantities $_{t}$ is the log of real GDP (GDPC96) divided by population 16 and over (CNP16OV). ${ }^{25}$ The growth rate of GDP is thus included in the VECM. The rate of inflation is obtained from the Consumer Price Index for all urban consumers all items (CPIAUCSL). ${ }^{26}$ In DSGE models with nominal rigidities, inflation is a jump variable reflecting expected marginal costs. So, we believe that this variable contains a sizeable amount of forward-looking component. In addition, this allows us to disentangle two stationary shocks. Finally, a "proxy" measure

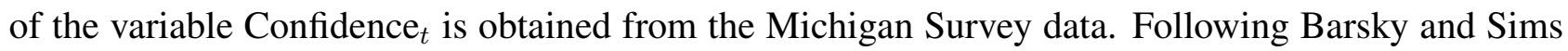
(2012), the survey that we first use is the responses to the question "Turning to economic conditions in the country as a whole, do you expect that over the next five years we will have mostly good times, or periods of widespread unemployment and depression, or what?". The variable is then obtained as the difference between the percentage giving a favourable answer and the percentage giving a negative answer, plus one hundred. This variable (E5Y) is taken in log. ${ }^{27}$ The sample period runs from 1960:1 to 2011:4.

\footnotetext{
${ }^{25}$ Other measures of real quantities, such as real per-capita consumption (non durables and services) and real per-capita investment (durables and private fixed investment) and labor productivity will be included in the model in replacement of GDP. See Section 4.

${ }^{26}$ We consider another measure of inflation, using the CPI all items less food and energy (CPILFESL). See Section 4.

${ }^{27}$ As in Barsky and Sims (2012), we will consider other measures of confidence: a second measure of confidence is obtained from a similar question for a shorter horizon of twelve months (E12M) and a third measure is an index of consumer sentiments (ICS) partly constructed from E5Y and E12M. We will also consider CEO confidence survey condition. See Section 4.
} 
We perform first ADF unit root tests on (adjusted) TFP and quantities (GDP, labor productivity, consumption, investment) and we cannot reject the null hypothesis. We also conduct ADF unit root tests on the first difference of these variables and then reject the null hypothesis. We then perform a cointegration test between TFP and the selected variables for quantities. We obtain from an ADF test on the residuals of the estimated relationship that the null hypothesis of no cointegration is rejected at conventional level. The cointegration parameter $\beta_{12}$ between TFP and quantities (GDP, investment, consumption, labor productivity) is then inserted in our VECM and the four structural shocks are identified using Identifications I-IV. We also perform ADF unit root test for inflation and the consumer confidence and we can reject the null hypothesis at conventional level.

\subsection{Dynamic Responses in the Benchmark Case}

The VECM is estimated with three lags, according to standard statistical criteria. Our results are modestly affected by other lag selection. The selected horizon $H$ in the second step is set to 40, so sentiments shock is identified as the main driver (among stationary shocks) of consumer confidence from impact to 10 years. Other choices for the horizon does not change so much our results. The estimated impulse response functions (IRFs) are reported in Figure 4. The shaded areas represent the $90 \%$ confidence bands obtained from bootstraps with 2000 replications.

\section{Surprise TFP Shock}

Let us first consider the dynamic responses of the four variables after a surprise TFP shock. The adjusted TFP jumps immediately and then slowly decreases to its long-run level. At the same time, GDP increases and the rate of inflation too. Note that the dynamic responses of inflation is significantly different from zero in the short-run. Our findings are similar to Barsky, Basu and Lee (2014) who obtain a positive and significant response of inflation during eight quarters. This surprising result is difficult to reconcile with sticky-price model, because a mean reverting TFP shock will decrease the marginal cost for several period. This is also inconsistent with Basu, Fernald and Kimball (2006) who show that inflation persistently decreases after a TFP shock. Anticipating upcoming results, this suggests that TFP includes another component (news shock in our setup) that can potentially reconcile our findings with the data. Finally, the consumer confidence increases on impact, but afterward the dynamic response is persistently negative. The surprise TFP shock does not seem to have a lot of explanatory power on consumer confidence.

News TFP Shock 
The dynamic responses after a news shock on TFP differ sharply see the right top panel of Figure 4. First, the adjusted TFP does not react on impact (by construction), stays around zero during two years and then increases very gradually. TFP reaches its new long-run value after more than ten years. This shape of the response highlights a slow diffusion process of a technology improvement (see Portier, 2014). We obtain a significantly positive response of output on impact followed by a rapid increase. This finding is consistent with the news-driven business cycles (see Beaudry and Portier, 2014), as output reacts immediately to an expected component in TFP. Since controversies concern the response of quantities to the news shock (Beaudry and Portier, 2006, 2014, Barsky and Sims, 2011, Barsky, Basu and Lee, 2014), we will investigate latter the response of other aggregates (investment, consumption, hours worked) to assess the robustness of this pattern. An important additional result is about the response of inflation to a "good" news shock. The rate of inflation drops immediately and gradually goes back to its steady state. Note that the response of inflation is precisely estimated. This finding is in line with Barsky and Sims (2011) and Barsky, Basu and Lee (2014) who obtain that news shock on TFP looks like a standard supply shocks. This results appears robust in all our experiments and perturbations of the benchmark case. The DSGE literature has not paid so much attention to this dynamic response of inflation, with the noticeable exceptions of Barsky and Sims (2009), Jinnai (2013) and Barsky, Basu and Lee (2014). In this latter paper, they show that real wage rigidity will help to reduce marginal cost and then inflation can drop after a news shock. Even more striking is the large and persistent response of consumer confidence to the news shock. This result is in contrast with the surprise TFP shock that has very limited and short-lasting effects on consumer confidence. The response is significantly different from zero for all the selected periods (10 years) after the shock. Our finding is in line with Barsky, Basu and Lee (2014) from a different SVAR setup, but we obtain a more persistent response of confidence. These results will be also confirmed when it comes to the variance decomposition and history of consumer confidence (see section 3.3).

\section{Sentiments Shock}

We concentrate our analysis on the effects of the sentiments shock, which constitutes the variable of interest in our SVAR setup. The dynamic responses after a sentiments shock are reported in the right bottom panel of Figure 4. Our findings give little support to the widespread belief that consumer confidence (and so a sentiments shock, given our identification scheme) matters a lot for aggregate fluctuations. ${ }^{28}$ First, GDP slightly decreases on impact and then displays a positive hump with a

\footnotetext{
${ }^{28}$ By construction, this shock has no impact effect on TFP, but all the responses after the shock are not significantly different from zero.
} 
peak after two years. However, the effect on GDP is rather limited if we compare the estimated response to those obtained after a news shock. Moreover, the dynamic response is not precisely estimated. Second, the rate of inflation increases a little after the sentiments shock, but again all the estimated responses are not different from zero. So neither quantities nor prices are affected by the sentiments shock. Third, the response of consumer confidence is large and persistently positive. The response of confidence to a sentiments shock (except in the short-run) appears similar to the one obtained after a news shocks. Together with the weak response of confidence to the surprise TFP and the remaining stationary shocks, this suggests that news and sentiments shocks are almost the sole drivers of consumer confidence.

\section{Remaining Stationary Shock (Demand Shock)}

Figure 4 also reports the dynamic responses after the remaining stationary shock. This shock has little effects on TFP (by construction zero on impact) and the dynamic responses are almost not different from zero for all the periods after the shock. So, our impact restriction does not seem to distort the shape of the response. ${ }^{29}$ The response of output displays a hump-shaped pattern and it is still positive two years after the shock. At the same time, the rate of inflation increases significantly during the same time span. So, this shock is highly pro-cyclical. We retrieve the persistent effects of stationary (demand) shocks already highlighted by the SVARs literature (Blanchard and Quah, 1989 and Cogley and Nason, 1995, Galí, 1999). ${ }^{30}$ In what follows, we will then label this shock as a demand shock. This shock has a small positive impact on consumer confidence followed by a negative effect for 10 quarters. Notice that the response of confidence is not precisely estimated.

\subsection{Contribution to Business Cycle}

To assess the contribution of identified shocks to business cycle, we conduct two exercises. First, we perform a standard variance decomposition for both TFP, quantities, inflation and consumer confidence. Second, we construct histories at business cycle frequencies for each variable and then investigate episodes for which these shocks matter.

Figure 5 reports the variance decomposition for the four variables. First, the measure of adjusted TFP is almost totally explained by the surprise TFP shock in the short-run. By construction, the three

\footnotetext{
${ }^{29}$ We have also investigated this issue and relaxed the zero restriction on impact for this shock. None of our findings is modified. See the discussion in footnote 31 and the results reported in the online appendix.

${ }^{30}$ This finding is also confirmed when one considers the effects of monetary policy and government spending shocks (see Christiano, Eichenbaum and Evans, 2005 and Galí, López-Salido and Vallés, 2007).
} 
other shocks have no effect on impact. As the number of periods after the shock increases, the share of the variance of TFP explained by the surprise TFP shock decreases and the share explained by the news shock gradually increases. Notice that the contribution of the two stationary shocks is virtually zero. Second, the surprise TFP shock and the labelled demand shock explained between $80 \%$ and $90 \%$ of the variance of GDP in the short-run (on impact and after one period). The share explained by the latter shock is about $35 \%$ at its peak and decreases as the number of periods increases, according to the long-run restriction. More interestingly, the same pattern applies for the surprise TFP shock. The news shock appears progressively as the main driver of output fluctuations, since its share exceeds $50 \%$ after two years and is around $90 \%$ after ten years. These findings are similar to those of Beaudry and Portier (2014). The sentiments shock has a negligible effect on GDP for all horizons. Third, the demand (40\%) and the news shocks (50\%) are the two main drivers of inflation. Barsky, Basu and Lee (2014) obtain a similar result for the contribution of the news shock to inflation. The effect of surprise TFP shock is very small in the short-run (just above 5\%) and the sentiments shock has again a limited effect (less than 5\%). Fourth, Figure 5 illustrates our identification strategy. Among the two transitory shocks, sentiments shock explains the bulk of the consumer confidence. Only two shocks accounts for the volatility of consumer confidence. In the short-run, the sentiments shock is the main driver (around 65\%), followed by the news shock (30\%). For longer horizons, the ranking is inverted, since the news shock accounts for more than $60 \%$ of the variance of consumer confidence after ten years, whereas the share of the sentiments shock falls to $35 \%$. This finding is in line to what obtained Barsky and Sims (2011) and Barsky, Basu and Lee (2014) in a SVAR setup. Importantly, our results confirm those of Barsky and Sims (2012) who obtained a similar conclusion from estimating a New Keynesian structural model. To sum up, the sentiments shock explains a tiny portion of aggregate fluctuations (quantities and prices) and this shock does not appears as the dominant shock of consumer confidence in the medium run. The identified sentiments shock seems more as an idiosyncratic component of the consumer confidence.

Another way to evaluate the relative contribution of the four identified shocks relies on the computation of the history for aggregate data. The history is obtained as follows. First, we feed the SVECM with only one of the identified structural shocks. We then perform dynamic simulations and then obtained a path for TFP, real per capita output, inflation and consumer confidence conditional on the selected shock. For each variable, we obtain the cyclical component (between 1.5 and 8 years) using a band pass filter. We then compare the cyclical component conditional on the selected innovation to the unconditional one. The procedure is then repeated for each shock. 
Figures 6-7 report the history of each variable (successively TFP, GDP, inflation and consumer confidence) for each shock (successively surprise TFP shock, news TFP shock, demand shock and sentiments shock). Grey areas represent the NBER recession dates. First, as it is clear from Figure 6 (top panel), TFP is essentially driven by the surprise TFP shock at business cycle frequencies. The news shock is not associated to fluctuations in TFP, reflecting its long-lasting effects on technology. The demand shock is weakly correlated with TFP, except in periods that follow the last US recession. This can reflects that the zero restriction on impact for demand shock should not be imposed. As noticed below, relaxing this restriction has no consequence for our main pictures. Second, the two main drivers of GDP are the news TFP shock and the demand shock (see Figure 6 bottom panel). The news shock is associated to output fluctuations in the seventies and the main economic downturns during this period (see Barsky, Basu and Lee (2014) for a similar finding). Conversely, the news shock plays no role during the Volker disinflation episode, nor during the great recession. For the period starting in the mid-eighties and ending just before 2007, the news shocks is essentially associated to booms in economic activity. The demand shock has a strong negative effect on output in the beginning of the eighties. This finding is consistent with the fact that the Volker disinflation was considered has a main source of the US recession in the early 1980s. Interestingly, the demand shock is also associated to the drop in output during the great recession. For these two episodes, the sentiments shock is totally absent and does not represent a drivers of output fluctuations. Concerning inflation (see the top panel of Figure 7), again the news and demand shocks are both important sources of fluctuations. The news shock explains the dynamic of inflation during the seventies, whereas the Volker disinflation originates from a negative demand shock, as well as the recent great recession. Notice that the surprise TFP shock cannot provide any explanation about inflation. The results with sentiments shock are mixed: for the seventies the sentiments shock is strongly negatively correlation with inflation, whereas the correlation appears positive since the mid-eighties. Finally, the inspection of Figure 7 (bottom panel) reveals that the news shock and the sentiments shock equally explain the consumer confidence. The news shock heavily explains the huge drop in consumer confidence in the mid-seventies and the two shocks equally reproduce the decrease in the early eighties. Notice that the recent crisis is not associated to a big fall in consumer confidence, compared to the mid-seventies and the early eighties. For the recent crisis period, the sentiments shock seems to have more explanatory power than the news shock. The two other shocks (unexpected TFP and demand shocks) cannot help to explain fluctuations in consumer sentiments. 


\section{Robustness}

We conduct various robustness exercises. First, we include factors in our SVAR and address the issue of non-fundamentalness. Second, without modifying the size of our SVAR, we investigate the role of conditioning variables. Third, we use another identification strategy of news shock by adapting the Barsky and Sims (2011) procedure in our two-step approach. Finally, we assess the sensitivity of our finding to data measurement (price, confidence measures). ${ }^{31}$

\subsection{A Quantitative Assessment of Non-Fundamentalness}

The relevance of SVARs to properly uncover structural shocks has been already addressed by the literature (see Cooley and Dwyer, 1998, Chari, Kehoe and MacGrattan, 2008, Christiano, Eichenbaum and Vigfusson, 2007 and Fève and Guay, 2010). ${ }^{32}$ However, the presence of new shocks raises additional problems related to non-fundamentalness/non-invertibility issues (Leeper, Walker and Yang, 2013). This problem occurs because actual variables used by the econometrician might not contain enough information to properly uncover structural shocks. As discussed in Beaudry and Portier (2014), this is an important issue in time series econometrics but we must distinguish the qualitative importance of the critique from its quantitative relevance. From a qualitative perspective, one may or may not find many situations (depending on the properties of the news process and the variables observed by the econometrician) for which the reduced form is non-invertible. The quantitative importance relies on the accuracy of SVARs even if the true data generating process is non-fundamental. This points has been highlighted by Sims (2012) who demonstrates via Monte-Carlo experiments that SVARs can yield reliable estimates of the true dynamic responses from DSGE models that are non-invertible. To address this quantitative issue, we adapt the simple procedure developed by Forni and Gambetti (2014) to our two-step approach. We proceed in the following four steps:

1. We estimate the VECM and apply our two-step approach to identify the structural shocks.

2. We regress the identified news shock on lagged values of different factors. If the test statistic does not reject the null hypothesis of orthogonality, then we stop. If not, we go to step 3.

\footnotetext{
${ }^{31}$ We have also relaxed the assumption that demand shocks cannot have an effect (on impact) on TFP (see Ben Zeev and Pappa, 2014, for a quantitative assessment). The demand shock has now an immediate effect on TFP but none of our previous results are affected. We have also investigate the robustness of the results to other sample selection. When we consider a shorter sample (1960-2006), i.e. excluding the recent crisis, we obtain the same findings (see the online appendix).

${ }^{32} \mathrm{~A}$ large part of the debate has concerned the identification of permanent unexpected technology shocks and their effect on hours worked.
} 
3. We include the relevant factors into our two-step approach and we identify the structural shocks.

4. Finally, we compare the estimated responses to news shock to those obtained without the relevant factors in the VECM.

Two remarks are worth noting. First, in step 3 of the procedure, we maintain identifications I-IV and we adapt these restrictions to the case of additional stationary variables. Second, we do not separately identify the remaining stationary shock (the shock that we continue to label as a demand shock) and those related to the stationary factors included in the VECM model. Identification can be obtained only if we impose additional restrictions among these shocks. This is not problematic for our purpose because we can still identify the news and sentiments shocks and we mainly concentrate our analysis on these shocks. For the variance decomposition exercise, the composite shock must be interpreted as a combination of stationary shocks with no long-run effect on TFP and quantities and these shocks explain the smallest part of the forecast error of confidence up to a certain horizon.

We use the 12 factors constructed at monthly frequency by Jurado, Ludvigson and $\mathrm{Ng}$ (2014) from a macro (132 macro series) and financial (147 financial series) datasets. The monthly data are then converted in a quarterly frequency by selecting the last month of the quarter. The Wald and Lagrange multiplier statistics are large and their p-value are almost zero. So the null hypothesis of orthogonality is rejected. At the same time, the coefficient of determination of this regression does not appear large $\left(R^{2}=0.38\right)$. We also investigate which factor contributes the more to this rejection. The fourth factor appears to have the largest explanatory power for the news shock. ${ }^{33}$ So, we repeat the test and then linearly project the news shock on a constant term and four lags of this factor. We still obtain large values for the Wald and Lagrange multiplier statistics and the null hypothesis is again rejected (the p-value is close to zero). Despite the rejection of orthogonality, the coefficient of determination of this regression is rather small $\left(R^{2}=0.14\right)$. This $R^{2}$ measures the share of the variance of news shocks explained by this most important factor. ${ }^{34}$ Anticipating on the next results, this suggests that non-invertibility is indeed an issue present in the data (the orthogonality is rejected), but its effect can remain quantitatively small (the coefficient of determination is small).

\footnotetext{
${ }^{33} \mathrm{We}$ find that the 9 th and 12 th factors are mildly significant but with a small coefficient of determination (around 4\%).

${ }^{34}$ See Beaudry, Fève, Guay and Portier (2015) about the use of the $R^{2}$ diagnosis for judging the severity of nonfundamentalness on the estimation of news shocks. In particular, they show when the $R^{2}$ associated with the sufficient information test of Forni and Gambetti (2104) is a better indication of the quantitative relevance of the nonfundamentalness problem than the significance level of the test itself.
} 
We now proceed with the third step and then include this factor in the VECM. We re-apply the orthogonality test by regressing the identified news shock in the five-variable model on a constant and four lags of the remaining eleven factors. Now, the test statistics (Wald and Lagrange multiplier) do not reject the null hypothesis at conventional level (with p-values at 41\%). So, in this Factor Augmented VECM the contribution of these factors to news shock is very small.

Finally, we compare the estimated responses of TFP, output and consumer confidence to unexpected TFP, news on TFP and sentiments shocks. Results are reported in Figure 8. The comparison with Figures 4-5 makes clear that the estimated responses are similar. Let us first concentrate on the news shock. Again, TFP increases gradually after a news shock, reflecting the slow diffusion of a technology improvement. GDP immediately jumps and the medium-run responses are identical in the benchmark VECM and the Factor Augmented VECM. An additional robust feature is the persistent decrease of inflation after a positive news shock. Finally, as in the benchmark case, the news shock have a positive and long-lasting effect on consumer confidence. As another illustration of the relevance of our results, we compute the correlation between news shocks identified from the benchmark case and from the Factor Augmented VECM. The correlation is large (0.80) and the two identified shocks are very similar. This similarity is further illustrated on Figure 9 where we plot the news shock from Factor Augmented VECM against news shock from the benchmark VECM. As it is clear from this figure, the two shocks are aligned on the 45 degree line. Now consider the sentiments shock (see Figure 8). This shock has still a small effect on quantities and prices and only strongly affects consumer confidence. These findings are confirmed by the variance decomposition exercise (see the bottom right panel in Figure 8), to be compared to Figure 5. The presence of a factor in the VECM does not alter our previous findings and all our conclusions are maintained. So, the important finding that the sentiments shock does not contribute to the cyclical behavior of prices and quantities is not modified when the non-fundamentalness is taken into account. Although present in the data, non-fundamentalness/non-invertibility does not quantitatively matter for our findings.

\subsection{Other conditioning variables}

We now investigate the role of conditioning variables. As previously noticed, conclusions about news shock must be more deeply inferred from the short-run responses of other aggregates. In addition, we want to assess if the conditioning variable modifies our main conclusions. We replace the GDP by investment, consumption and labor productivity, successively. We use the same VECM (1) as before and we maintain the identification scheme. The number of lags is also the same as before. 
Again, changing the number of lags in the VECM does not modify our results. We just need to adjust for the cointegration relationship (i.e. adjusting the cointegration parameter $\beta_{12}$ ) between the TFP and the new variable that represents quantities (investment, consumption and labor productivity). We conduct another conditioning exercise in which we replace inflation by hours worked. The identified stationary shock is a shock that does not affect TFP and GDP in the long-run, has no effect on TFP on impact and yields the smaller contribution to confidence. ${ }^{35}$

\section{Investment}

Let us first consider the dynamic responses with the real per capita investment (defined as the sum of private fixed investment and durables) instead of GDP. The dynamic responses of TFP, inflation and consumer confidence after each shock are similar to what we obtained with the GDP in SVAR. The sole difference concerns the size of the response of investment to each shock, reflecting the higher volatility of investment compared to output. In the line with Beaudry and Portier $(2006,2014)$, we obtain that investment instantaneously increases and very quickly reaches its long-run value after a positive news shock. At the same time, TFP increases gradually. So, our results are supportive of the news-driven business cycle. Again, the consumer confidence highly and persistently reacts to "good" news. The response of inflation to a news shock is persistently negative, as in the benchmark case. The response of investment to a demand shock displays a hump-shape pattern. Inflation still increases, but its effect is not precisely estimated. The demand shock has virtually no effect on consumer confidence. The response of investment to a sentiments shock is hump-shaped and prices increase. However, the dynamic responses are not different from zero. Consumer confidence strongly reacts on impact to a sentiments shock but the response displays less persistence, compared to the benchmark case. Figure 10 reports the variance decomposition for the four variables. The variance decomposition of TFP is almost same as in the benchmark exercise. Two differences are worth noting. First, the (transitory) demand shock remains the main driver of investment during three years. For more periods after the shock, the news shock becomes the larger contributor. Second, the sentiments shock has a larger but rather limited effect on investment (its larger contribution never exceeds $15 \%$ ).

\section{Consumption}

Now, we consider real per capita consumption in our VECM. This variable is defined as the sum of non-durable and services expenditures and then is divided by population 16 and over. Concerning the

\footnotetext{
${ }^{35}$ To save space, we only report the variance decomposition. Figures of dynamic responses and history are included in the online appendix.
} 
dynamic responses, the picture is almost the same as we obtained with GDP. ${ }^{36}$ The sentiments shock has limited effects on consumption and inflation, not precisely estimated. Sentiments shock only affects consumer confidence, without any apparent propagation effect on main aggregates. Figure 11 reports the variance decomposition for TFP, consumption, inflation and consumer confidence, respectively. The variance decomposition of TFP is almost identical to the benchmark case: the unexpected TFP shock explains almost totally the variance of TFP in the short-run and the share of news shock on TFP increases with the horizon. Concerning real per capita consumption, the news shock is the main driver ( $60 \%$ on impact and more than $95 \%$ after five years). The sentiments shock contributes in the short-run (around 20\%), but its effects quickly decreases. Concerning inflation, the main difference is that demand shock explains the larger share of its variance (more than 50\%) and the contribution of the news shocks is reduced compared to the benchmark case. As in the previous cases, news and sentiments shocks account for most of the volatility of consumer confidence.

\section{Labor Productivity}

The last variable that we consider for quantities is the labor productivity. Labor productivity is obtained by dividing real per capita GDP by the average weakly total hours (see Francis and Ramey, 2009). The results are similar as what we obtained with GDP. We only discuss the variance decomposition. The labor productivity is almost totaly governed by the two (unexpected and expected) TFP shocks (see Figure 12). Again, the news and demand shocks equally explain inflation. The main difference with the benchmark case concerns the variance decomposition of the consumer confidence. We obtain that the sentiments shock explains more than $80 \%$ of consumer confidence. This has no consequence for the other variables as this shock weakly affects both quantities and prices.

\section{Hours Worked}

Finally, we consider hours worked as another relevant variable for extracting useful information about sentiments. We use again real per capita GDP for the quantities, but we replace inflation by the $\log$ of hours worked. As in the previous experiment, we use the average weakly total hours. So, the vector $y_{t}$ rewrites $y_{t}=\left(\mathrm{TFP}_{t}, \mathrm{GDP}_{t}, \operatorname{Hours}_{t}, \text { Confidence }_{t}\right)^{\prime}$. The shock that we identify with hours worked is labeled labor market shock. As before, this shock is restricted to have no effect (on impact) on TFP and explains the smallest share of consumer confidence up to horizon 40. The dynamic responses of TFP, output and consumer confidence to a surprise TFP shock are almost identical to

\footnotetext{
${ }^{36}$ As for investment, inflation decreases after a news shocks, making the negative response a robust fact (see Barsky, Basu and Lee, 2014).
} 
those obtained in the benchmark model. The response of hours on impact is positive, but rather small. Then hours display a positive hump-shaped pattern. Note that the response is not precisely estimated as the confidence interval is very large, except on impact. This is the consequence of modeling hours in level, when it contains highly persistent low frequency components (see Chaudourne, Fève and Guay, 2014). The estimated responses of TFP, output and consumer confidence to a news shock are again close to those obtained before. The difference concerns the large and uninformative confidence interval. Note that the response of hours worked on impact is small, but hours quickly increase. The responses of TFP and output to a (transitory) labor market shock are similar as what we obtained before. The sole difference is the response of consumer confidence which is now negative in the short-run. Finally, the responses of TFP and output to a sentiments shock are in line with the benchmark model. Note that the responses of output and hours to this shock are very similar. The main difference concerns the response of consumer confidence which is smaller. Concerning the variance decomposition (see Figure 13), we obtain almost the same conclusions for TFP and GDP. The labor market shock is an important contributor of output variance in the short-run. This shock explains almost all the variance of hours on impact, but the news shock is gradually the main contributor of hours. This finding is in line with Beaudry and Lucke (2010). The sentiments shock again explains very little of the TFP, GDP and hours worked variances.

\subsection{Another Identification Strategy}

According to the previous results, the news shock appears as the key driver of quantities-prices fluctuations and it is thus legitimate to assess the robustness of our result to alternative identification strategies of this shock. Here, we follow Barsky and Sims (2011) and we departs from our long-run restrictions and estimate a VAR in levels. We use the same variables as in our benchmark setup, i.e. the model includes TFP, GDP, inflation and consumer confidence. We still impose that only the unexpected TFP shock can have an effect on current TFP. Among the three other shocks without an effect on current TFP, the news shock is identified as the shock that yields the largest contribution to the TFP for a given horizon. Finally, we use our two-step approach to disentangle the demand and sentiments shocks.

A direct comparison of Figure 14 with Figure 5 (Variance decomposition) makes clear that the identification strategy of news shocks does not modify our previous findings. ${ }^{37}$ Concerning the dy-

\footnotetext{
${ }^{37}$ We have also investigated the role of the selected horizon. None of our results are altered. We notably obtain that the Barsky and Sims identification yields almost the same results as our benchmark case when the horizon is large.
} 
namic responses, we still obtain a gradual increase in TFP together with an immediate jump in GDP after a positive news shock. Again, inflation persistently decreases and consumer confidence persistently increases after this shock. The demand shock yields a positive hump-shaped response of output and an increase in prices. Finally, aggregate variables react very modestly to the sentiments shock. This latter shock only affects consumer confidence. The variance decomposition shows very similar results as before. ${ }^{38}$ The sentiments shock explains almost zero of the variance of TFP and GDP and a small portion of inflation (around 10\%). This shock contributes a lot to the variance of the consumer confidence in the short-run, but ten periods after the shock, the share of the news shock is above $60 \%$.

\subsection{Data Measurement}

We now assess the role plays by the data measurement. To save space, we only report the variance decomposition (see Figure 15). First, we replace the Consumer Price Index all commodities by the Consumer Price Index less food and energy. The role of energy prices appears to be of first importance, because its cyclical pattern has changed quite a lot. During the seventies and the early eighties, energy prices were countercyclical consecutive to the successive oil shocks. Conversely, these prices became procyclical afterwards as the world economic growth (notably emerging economies) has led to an upward pressure. Energy prices can thus potentially contaminate our identification of supply and demand shocks. This is not the case. As shown in the upper left panel of Figure 15, the results are the same. The sole difference is that demand shock contributes more to the variance of inflation. Second, since the confidence variable is central in our analysis, it will legitimate to assess the sensitivity of our results to other measures. We replace our measure of consumer confidence E5Y by the a second measure of confidence obtained from a similar question for a shorter horizon of twelve months (E12M) and an index of consumer sentiments (ICS). The top right panel of Figure 15 reports the results with E12M and the bottom left with ICS. Compared to the benchmark case, the pictures are almost the same. The sole difference concerns the contribution of the sentiments shock to GDP that becomes larger in the short-run (around 25\%) with the variable E12M. We also consider a measure of confidence related to the business sector. We use CEO Confidence-survey conditions in six months as a proxy for sentiments. The results are reported in the bottom right panel of Figure 15. As it is clear from this figure, the main results are maintained. The main driver of GDP is still the surprise TFP shock in the short-run and the news shock explain most of the variance of output as the number

\footnotetext{
${ }^{38}$ The main difference with our benchmark setup concerns the contribution of the (transitory) demand shock to the variance of GDP in the short-run. In the SVECM, this contribution is around 35\%, whereas it exceeds $65 \%$ with the Barsky and Sims identification strategy. This is also confirmed by the history. See Figures in the online appendix.
} 
of periods after the shock increases. The demand shock explains a small share of output volatility, but a sizeable part on inflation. Finally, the sentiments shock contributes very little to quantities and prices. This shock only explains the volatility of business sector confidence.

\section{Conclusion}

The main driving forces of the business cycle are still the subject of much debate and controversy. We found that a SVAR incorporating a measure of confidence together with aggregate variables (TFP, GDP, consumption, investment, labor productivity and hours) predicts five main outcomes. First, sentiments shock explains very little of output and inflation. Second, the news and sentiments shocks equally contribute to consumer (and business sector) confidence. Third, the news shock on TFP accounts for most of the variance of quantities. Fourth, the transitory shock (labelled as a demand shock) represents a sizeable part of fluctuations in the short-run. Fifth, news on TFP and demand shocks are almost the sole drivers of inflation. These findings are robust to non-fundamentalness, conditioning variables, alternative identification strategy and data measurement. Our results from a flexible SVAR model show that the news story of the business cycles, as advocated by Beaudry and Portier (2006) and (2014) remains a very plausible source of aggregate fluctuations. At the same time, the sentiments shock, identified as the main contributor of confidence at business cycle frequencies seems to play a minor role.

Our findings are somewhat disappointing concerning the contribution of the sentiments shock to macroeconomic fluctuations. We do not think that our identification scheme introduces a bias against this potential driving source. The proposed identification strategy is flexible and does not restrict the effect of the type of shock as it can freely impact macroeconomic variables. The identification scheme only imposes that sentiments represent the main contributor of confidence up to a given horizon. In addition, our results are insensitive to the selected horizon. As usual in the SVAR literature, the absence of relevant informative variables can lead to miss some important transmission channels. However, we have thoroughly investigated many alterations of our setup and none of the alternatives yield a different picture. 


\section{References}

[1] Angeletos, M., F. Collard and H. Dellas (2014) "Quantifying Confidence”, NBER Working Paper 20807, National Bureau of Economic Research, Inc.

[2] Angeletos, M. and J. La'o (2013) “Sentiments”, Econometrica, vol. 81(2), 739-779.

[3] Barsky, R. and E. Sims (2011) "News Shocks and Business Cycles," Journal of Monetary Economics, vol. 58(3), 273-289.

[4] Barsky, R. and E. Sims (2012) "Information, Animal Spirits, and the Meaning of Innovations in Consumer Confidence," American Economic Review, vol. 102(4), 1343-1377, June.

[5] Barsky, R., S. Basu, and K. Lee (2014): "Whither News Shocks?," forthcoming in NBER Macroeconomics Annual 2014, ed. by J. Parker, and M. Woodford, vol. 29. University of Chicago Press.

[6] Basu, S., J. Fernald and M. Kimball (2006) "Are Technology Improvements Contractionary?," American Economic Review, American Economic Association, vol. 96(5), 1418-1448, December.

[7] Beaudry, P. and F. Portier (2005) "The News View of Economic Fluctuations: Evidence from Aggregate Japanese data and Sectoral US Data," Journal of the Japanese and International Economics, vol. 19(4), 635-652.

[8] Beaudry, P. and F. Portier (2006) "Stock Prices, News, and Economic Fluctuations," American Economic Review, vol. 96(4), 1293-1307, September.

[9] Beaudry, P. and F. Portier (2014) “News Driven Business Cycles: Insights and Challenges," Journal of Economic Literature, 52(4), 993-1074.

[10] Beaudry, P. and B. Lucke (2010) "Letting Different Views about Business Cycles Compete," in NBER Macroeconomics Annual 2009, ed. bu D. Acemoglu, K. Rogoff and M. Woodford, Vol. 24, 413-455, National Bureau of Economic Research, Inc.

[11] Beaudry P., P. Fève, A. Guay and F. Portier (2015) "When is Nonfundamentalness in VARs a Real Problem? An Application to News Shocks,", NBER Working Papers 21466, National Bureau of Economic Research, Inc.

[12] Benhabib, J., P. Wang and Y. Wen (2015) "Sentiments and Aggregate Demand Fluctuations,", Econometrica, 83(2), 549-û585. 
[13] Benhabib, J., and R. Farmer (1994) "Indeterminacy and increasing returns," Journal of Economic Theory, 63(1), 19-41.

[14] Ben Zeev, N. and E. Pappa (2014) "Multipliers of Unexpected Increases in Military Spending: All Quiet on the Demand Side Front", mimeo EUI.

[15] Blanchard, O.J. (1993) "Consumption and the Recession of 1990-1991," American Economic Review, American Economic Association, vol. 83(2), 270-74, May.

[16] Blanchard, O. J., J.-P. L’Huillier, and G. Lorenzoni (2013) "News, Noise, and Fluctuations: An Empirical Exploration,” American Economic Review, vol. 103(7), 3045-70, December.

[17] Blanchard, O. J., and D. Quah (1989) "The Dynamic Effects of Aggregate Demand and Supply Disturbances," American Economic Review, 79(4), 655-673.

[18] Chari, V., P. Kehoe, and E. McGrattan (2008) "Are Structural VARs with Long-Run Restrictions Useful in Developing Business Cycle Theory?,' Journal of Monetary Economics, 55(8), 13371352.

[19] Chaudourne, J., P. Fève and A. Guay (2014) "Understanding the Effect of Technology Shocks in SVARs with Long-Run Restrictions," Journal of Economic Dynamics and Control, Elsevier, vol. 41(C), 154-172.

[20] Christiano, L., M. Eichenbaum and L. Evans (2005) "'Nominal Rigidities and the Dynamic Effects of a Shock to Monetary Policy," Journal of Political Economy, University of Chicago Press, vol. 113(1), 1-45, February.

[21] Christiano, L., M. Eichenbaum and R. Vigfusson (2007) “Assessing Structural VARs," in NBER Macroeconomics Annual 2006, ed. by D. Acemoglu, K. Rogoff and M. Woodford, Volume 21, 1-106, National Bureau of Economic Research, Inc.

[22] Cochrane, J. H. (1994) "Shocks," Carnegie-Rochester Conference Series on Public Policy, 41(1), 295-364.

[23] Cooley, T., and M. Dwyer (1998) "Business Cycle Analysis without much Theory: A Look at Structural VARs," Journal of Econometrics, 83, 57-88.

[24] Farmer, R. (1999) Macroeconomics of Self-fulfilling Prophecies, 2nd Edition, MIT Press Books, The MIT Press, edition 2, August. 
[25] Farmer, R. (2012) "Confidence, Crashes and Animal Spirits," Economic Journal, Royal Economic Society, vol. 122(559), 155-172.

[26] Fernald, J. (2012) “A Quarterly, Utilization-Adjusted Series on Total Factor Productivity," unpublished manuscript, Federal Reserve Bank of San Francisco.

[27] Fernandez-Villerde, J, J. Rubio-Ramirez, T. Sargent, and M. Watson. (2007) “ABCs (and Ds) of Understaning VARs," American Economic Review 97(3), 1021-1026.

[28] Fève, P., and A. Guay (2010) "Identification of Technology Shocks in Structural VARs," Economic Journal, 120(549), 1284-1318.

[29] Forni, M., and L. Gambetti (2014) "Sufficient Information in Structural VARs" Journal of Monetary Economics, 66, 124-136

[30] Forni, M., L. Gambetti, M. Lippi, and L. Sala (2013) "Noisy News in Business Cycles," mimeo, Universit'a di Modena e Reggio Emilia, Universitat Autonoma de Barcelona, Universit'a di Roma La Sapienza and Universit'a Bocconi.

[31] Forni, M., L. Gambetti, and L. Sala (2014) "No News in Business Cycles," The Economic Journal, 124, 1168-1191.

[32] Francis, N., M. Owyang, J. Roush and R. DiCecio (2012), “A Flexible Finite-Horizon Alternative to Long-run Restrictions with an Application to Technology Shocks," forthcoming, Review of Economics and Statistics.

[33] Francis, N., and V. Ramey (2009) "Measures of per Capita Hours and their Implications for the TechnologyûHours Debate", Journal of Money, Credit and Banking, 41(6), 1071-1097.

[34] Fujiwara, I., Y. Hirose, and M. Shintani (2011) “Can News Be a Major Source of Aggregate Fluctuations? A Bayesian DSGE Approach,” Journal of Money, Credit and Banking, 43(1), 1-29.

[35] Galí, J. (1999) “Technology, Employment, and the Business Cycle: Do Technology Shocks Explain Aggregate Fluctuations?," American Economic Review, American Economic Association, vol. 89(1), 249-271, March.

[36] Galí J. D. López-Salido and J. Vallés (2007) "Understanding the Effects of Government Spending on Consumption," Journal of the European Economic Association, MIT Press, vol. 5(1), 227270, 03. 
[37] Gouriéroux, C. and A. Monfort, (2015), "Revisiting Identification and Estimation in Structural VARMA Models," CREST working paper.

[38] Hall, R. (1993) "Macro Theory and the Recession of 1990-1991," American Economic Review, vol. 83(2), 275-79, May.

[39] Jaimovich, N. and S. Rebelo (2009) "Can News about the Future Drive the Business Cycle?," American Economic Review, vol. 99(4), 1097-1118, September.

[40] Jinai, R. (2013) “News Shock and Inflation,” Economics Letters, 119(2), 176-179.

[41] Jurado K., S. Ludvigson and S. Ng (2014) "Measuring Uncertainty", forthcoming American Economic Review.

[42] Khan, H., and J. Tsoukalas (2012) "The Quantitative Importance of News Shocks in Estimated DSGE Models," Journal of Money, Credit and Banking, 44(8), 1535-1561.

[43] Leeper, E., T. Walker and S. Yang (2013) "Fiscal Foresight and Information Flows," Econometrica, Econometric Society, vol. 81(3), 1115-1145.

[44] Lorenzoni, G. (2009) "A Theory of Demand Shocks", American Economic Review, 99(5),: 2050-84.

[45] Lütkepohl, H. (2007) New Introduction to Multiple Time Series Analysis, Springer.

[46] Matsusaka, J. and A. Sbordone (1995) "Consumer Confidence and Economic Fluctuations," Economic Inquiry, Western Economic Association International, vol. 33(2), 296-318, April.

[47] Portier, F. (2014) “A Comment on Whither News Shocks? by Barsky, Basu \& Lee”, forthcoming in NBER Macroeconomics Annual 2014, ed. by J. Parker, and M. Woodford, vol. 29. University of Chicago Press.

[48] Schmitt-Grohé, S., and M. Uribe (2012) "What's News in Business Cycles," Econometrica, 80(6), 2733-2764.

[49] Shapiro, M. and M. Watson (1988) "Sources of Business Cycle Fluctuations," in NBER Macroeconomics Annual 1987, ed. by S. Fischer, 111-156. 
[50] Sims, E. R. (2012) “News, Non-Invertibility, and Structural VARs,” Working Papers 013, University of Notre Dame, Department of Economics, forthcoming in Advances in Econometrics, Vol. 28, DSGE Models in Macroeconomics - Estimation, Evaluation, and New Developments.

[51] Stock, J. and M. Watson (1988) “Testing For Common Trends," Journal of the American Statistical Association, December 1988, 83, 1097-1107.

[52] Uhlig, H. (2003) “What Drives GNP?” Unpublished manuscript. 
Table 1: Parameter values

\begin{tabular}{lc}
\hline \hline Subjective Discount Factor & 0.99 \\
Capital Share & 0.33 \\
Depreciation Rate & 0.025 \\
Growth Rate of TFP & 0.0036 \\
Inverse of the Frish Elasticity of Labor Supply & 1 \\
Price Markup & $20 \%$ \\
Adjustment Costs on Prices & 10 \\
Persistence of monetary Policy Shock & 0.6 \\
S.E. of unexpected TFP Shock & 0.0050 \\
S.E. of news shock on TFP & 0.0025 \\
S.E. of noisy news shock on TFP & 0 or 0.025 \\
S.E. of monetary policy shock & 0.0020 \\
S.E. of idiosyncratic sentiments shock & 0 or 0.0025 \\
S.E. of measurement error on sentiments & 0 or 0.0001 \\
\hline \hline
\end{tabular}



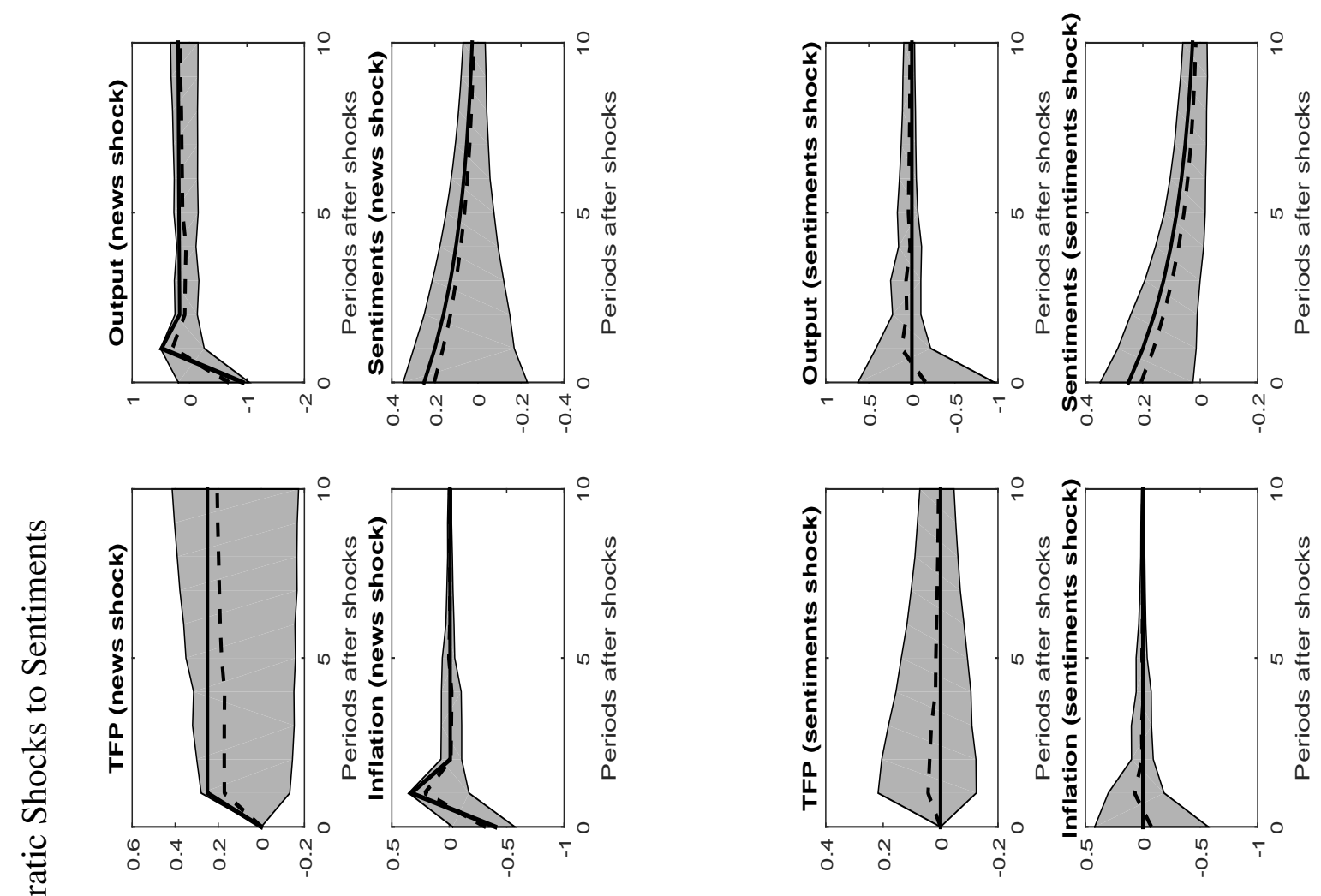

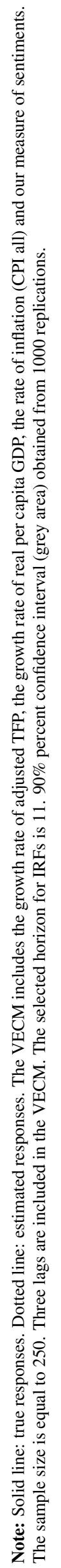



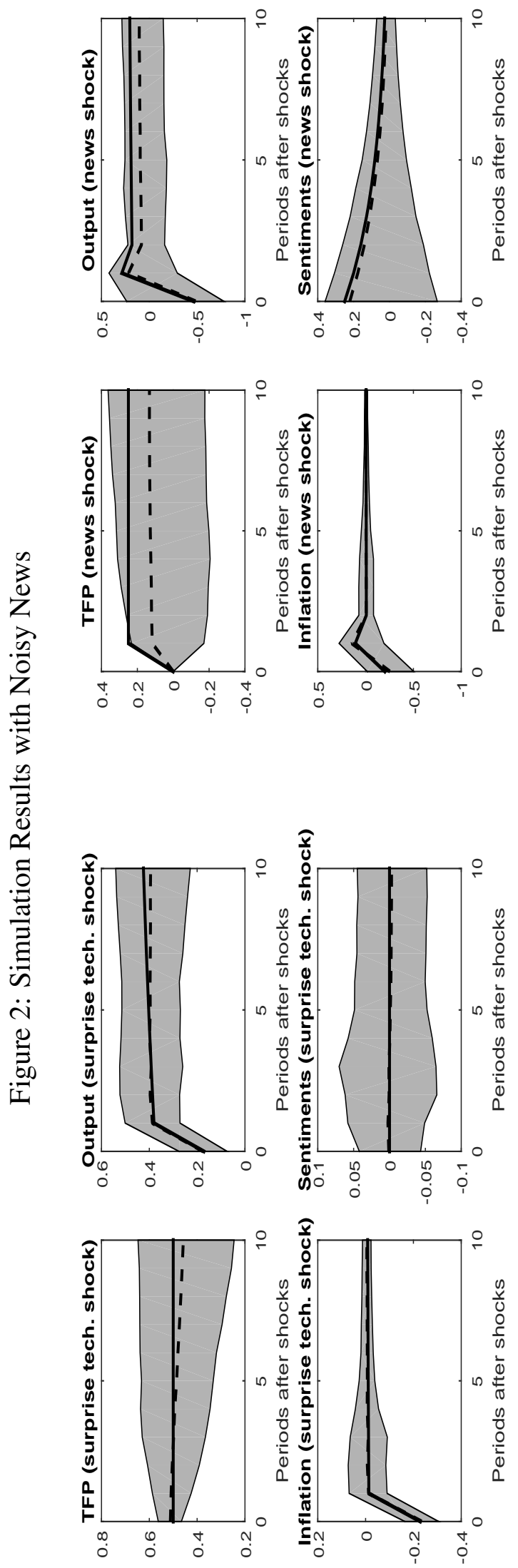
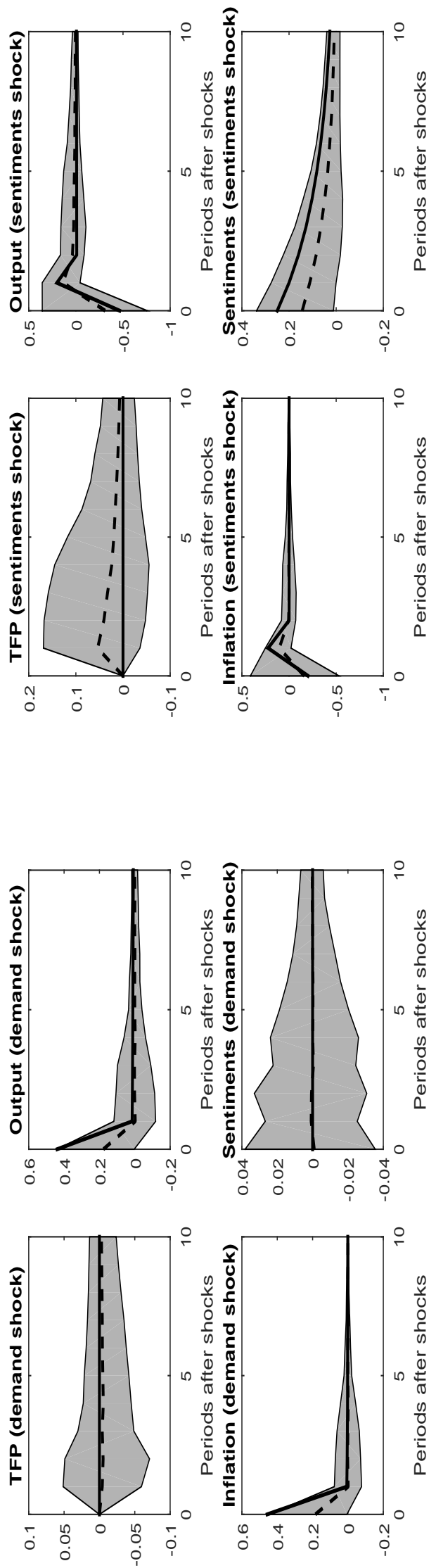

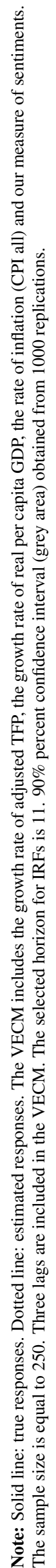



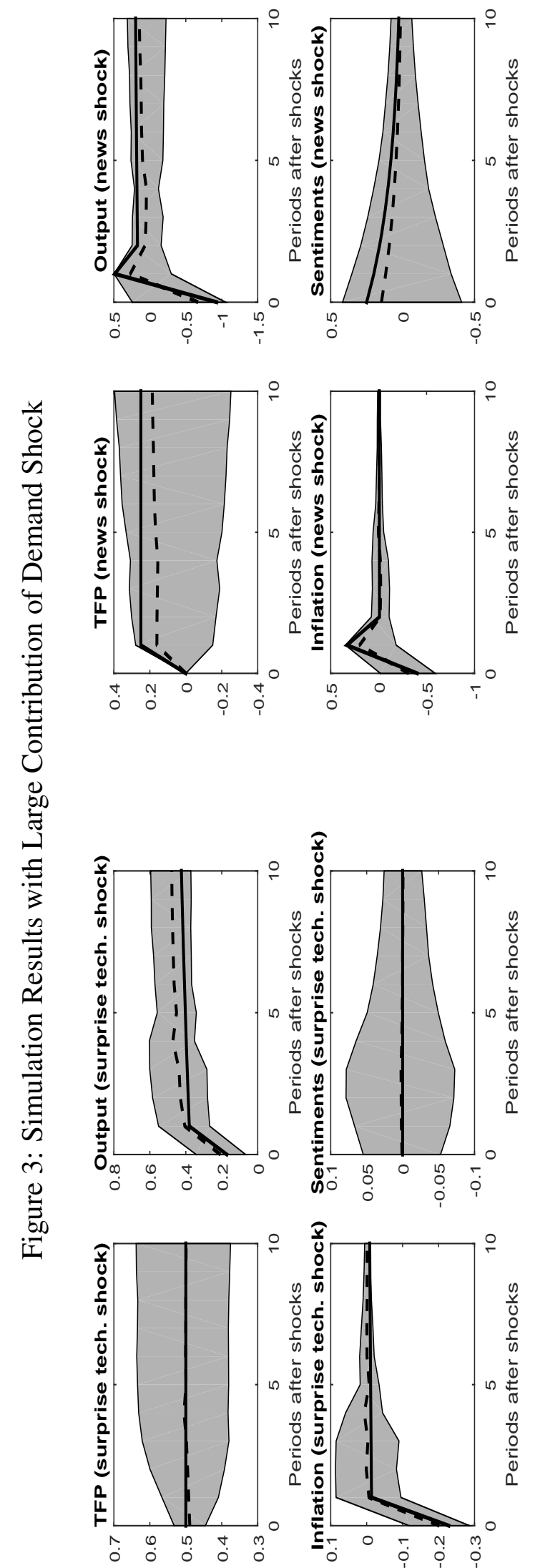
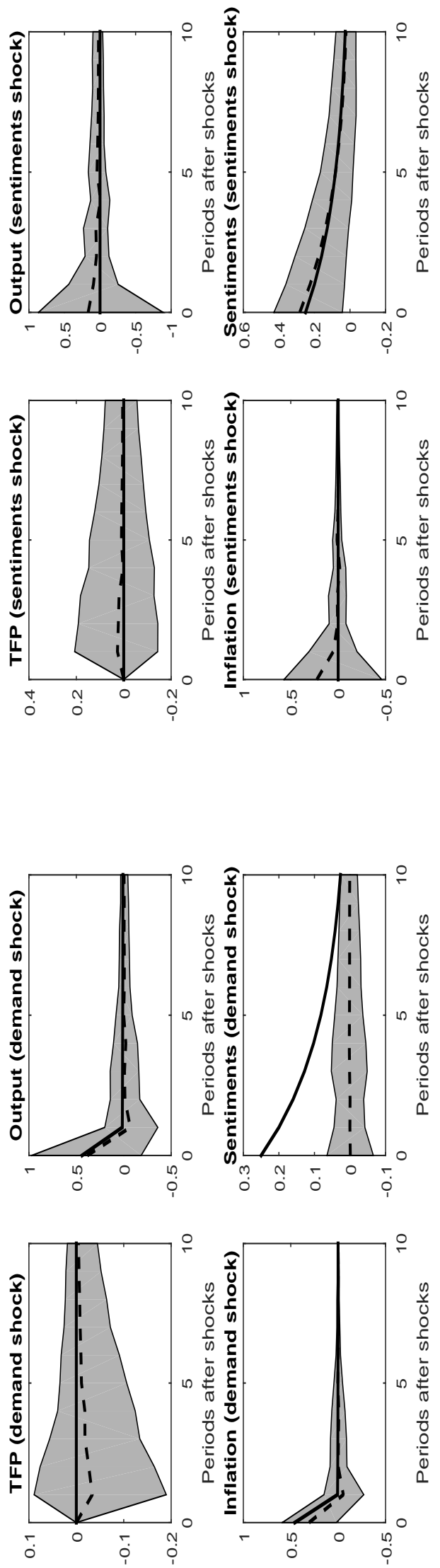

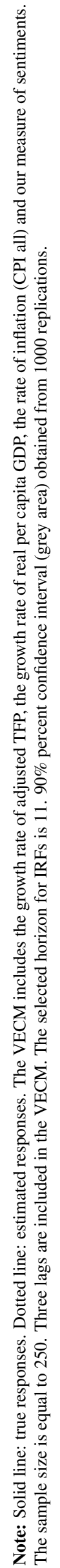



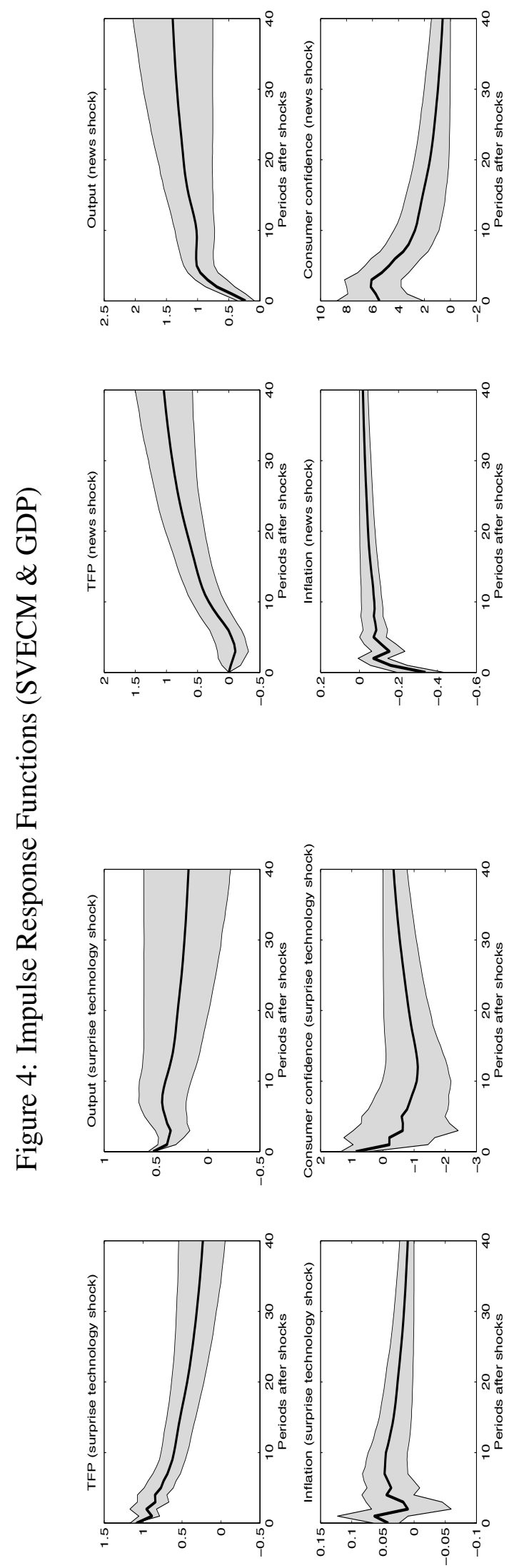

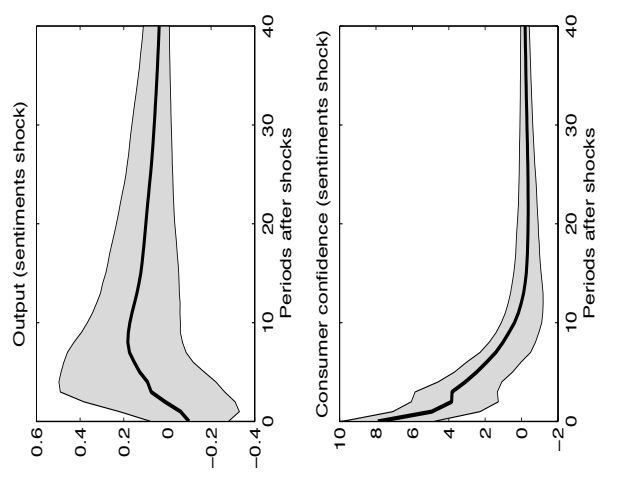

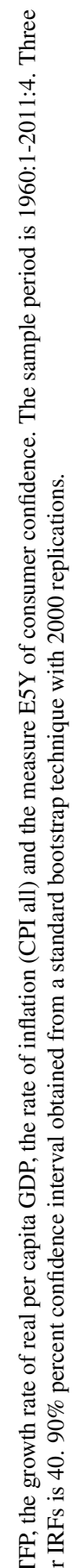
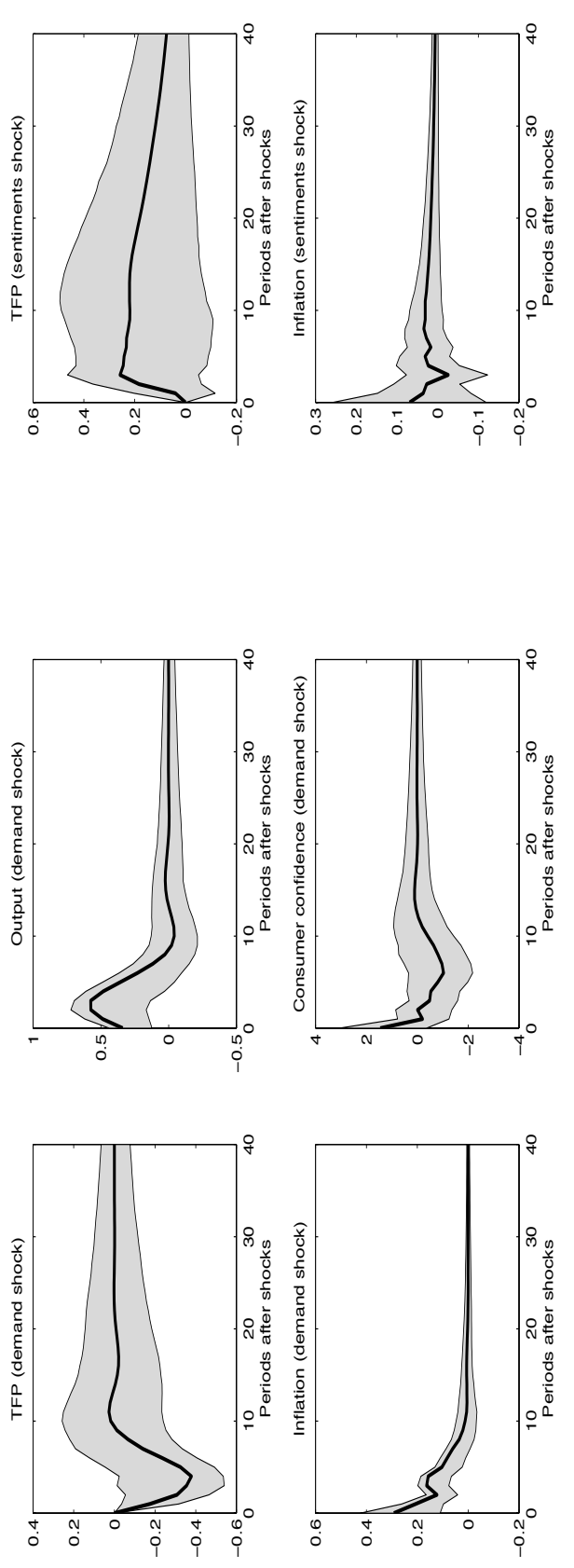

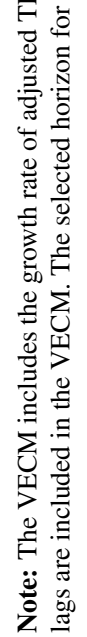


Figure 5: Variance Decomposition (SVECM \& GDP)
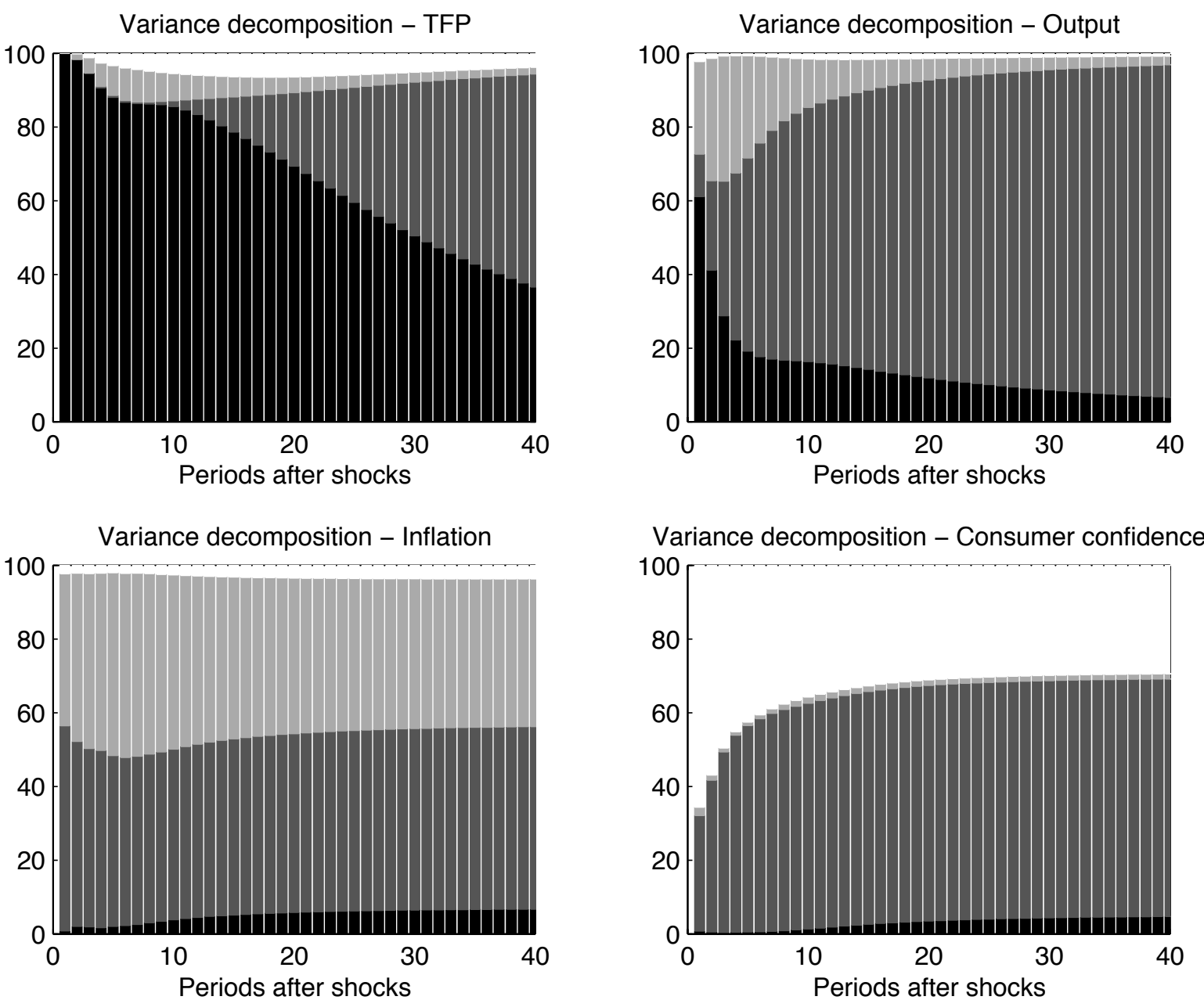

Note: The VECM includes the growth rate of adjusted TFP, the growth rate of real per capita GDP, the rate of inflation (CPI all) and the measure E5Y of consumer confidence. The sample period is 1960:1-2011:4. Three lags are included in the VECM. The selected horizon for IRFs is 40 . The white area corresponds to the share of variance explained by the sentiments shock, the light grey area to the demand shock, the dark grey area to the news shock on TFP and the dark area to the surprise shock on TFP. 

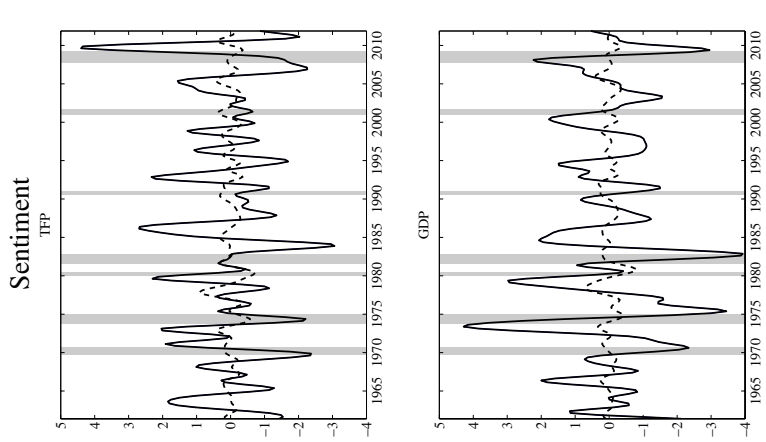

宅 导 $\lambda \dot{0}$ चี in . ฮี $x$ 동

艺

ธี ‡
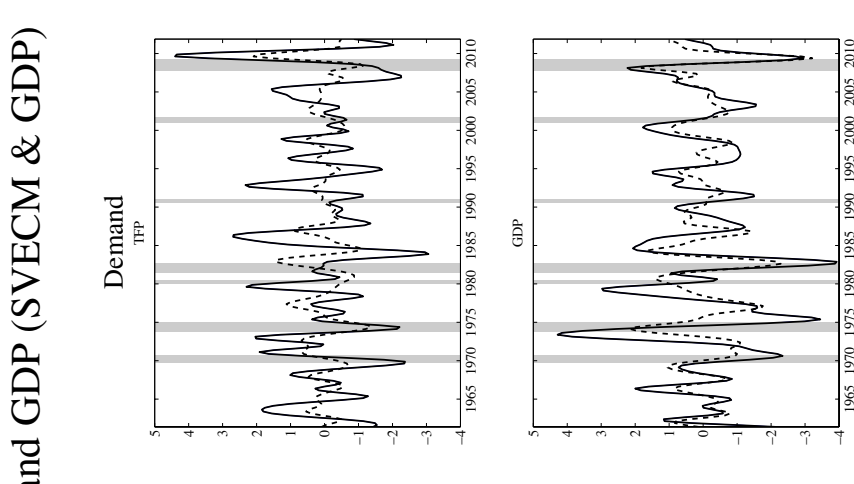

है

๘ 를 3 क Ð 岂 छ ลี on $\stackrel{\Xi}{\Xi}$

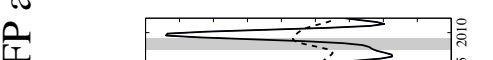

庄

눙

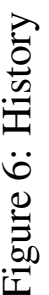
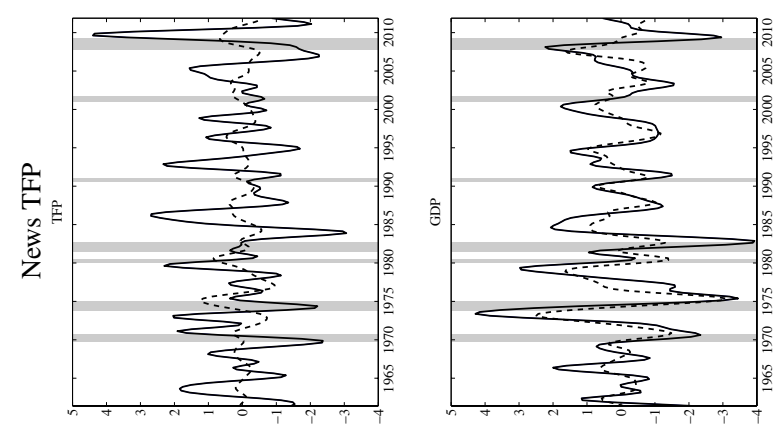

의.

氖

क क

苛

흉

릉

.

ำ

$\pm$

4
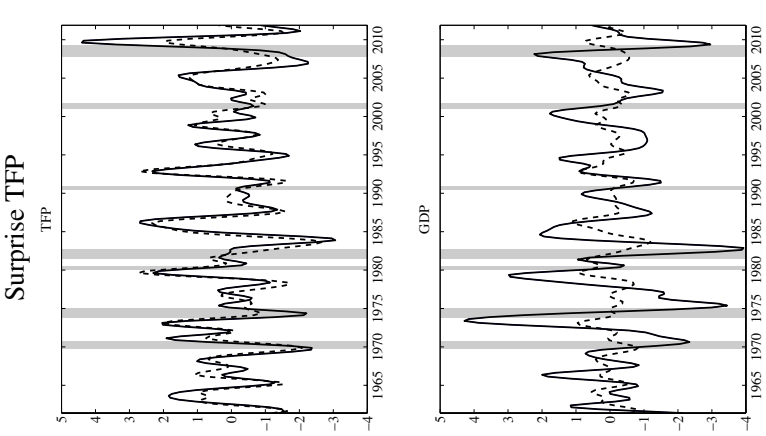

氙

응

घี

융

금

긍 응

웅

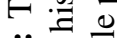

旁高敦 


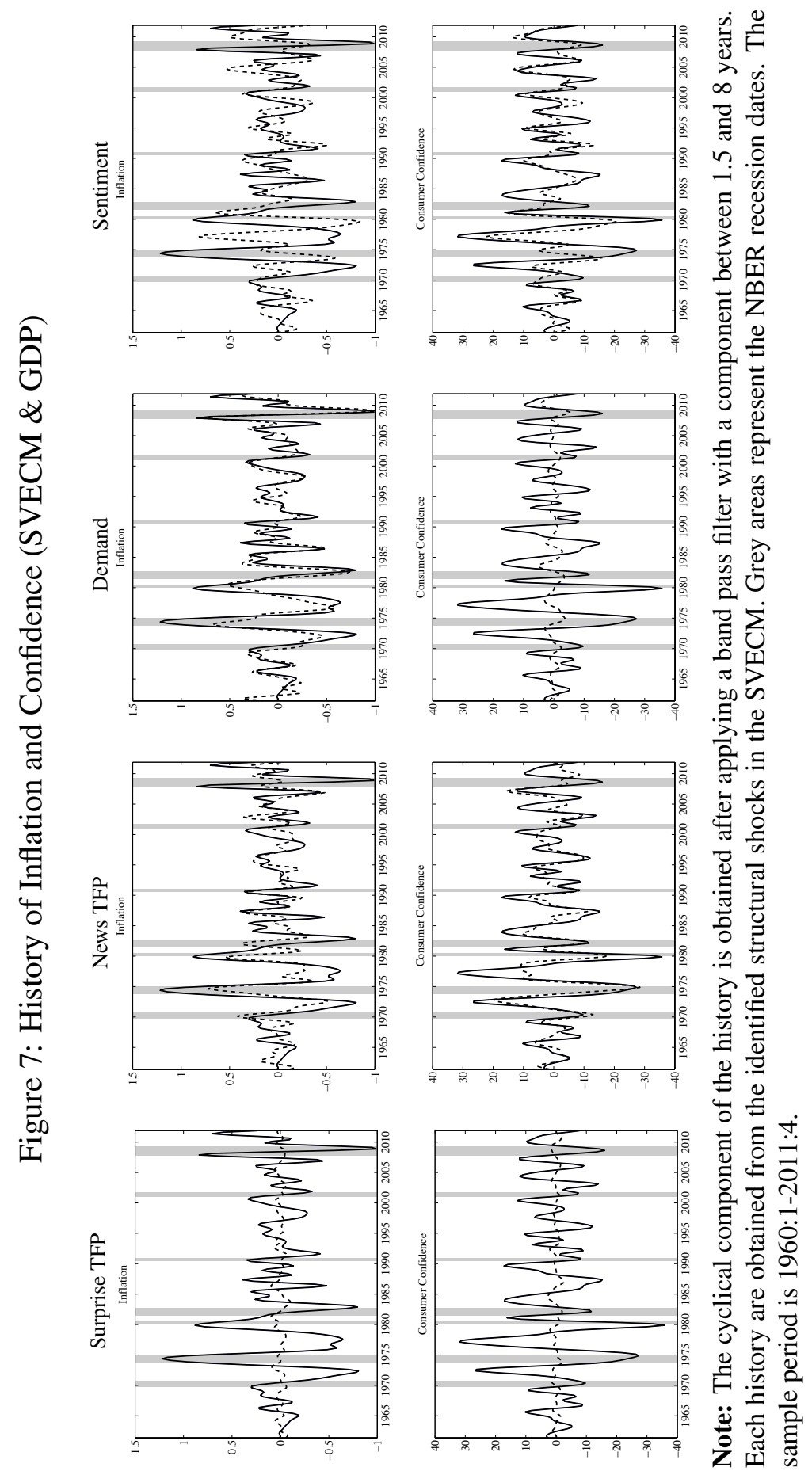



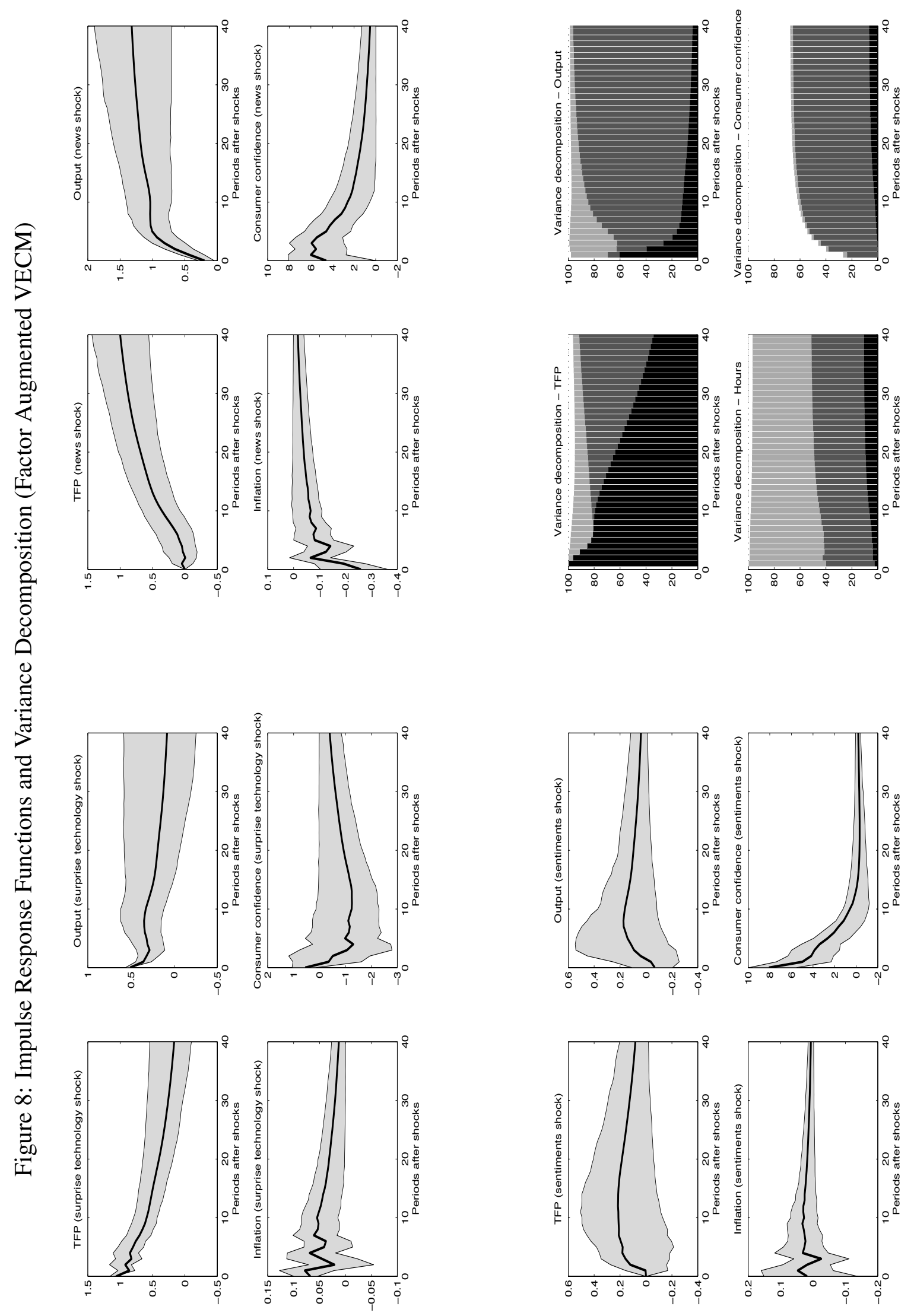

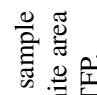

홀

용

进边

可 흔

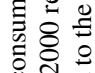

㻤焉

空 兰

을

㺃

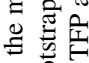

영

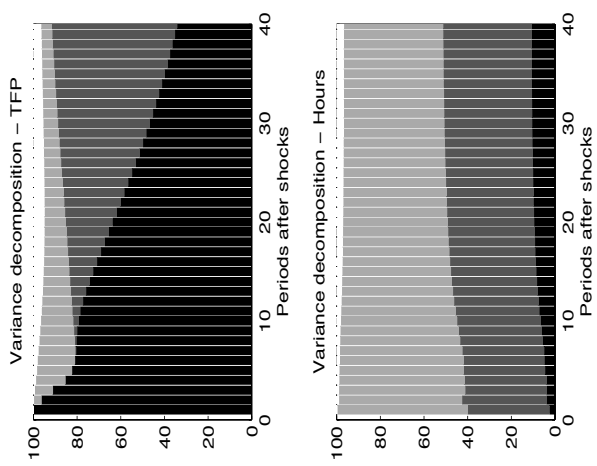

悹

㱐

言苛

已.

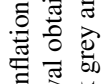

总

考

吾

Oิ

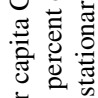

迟

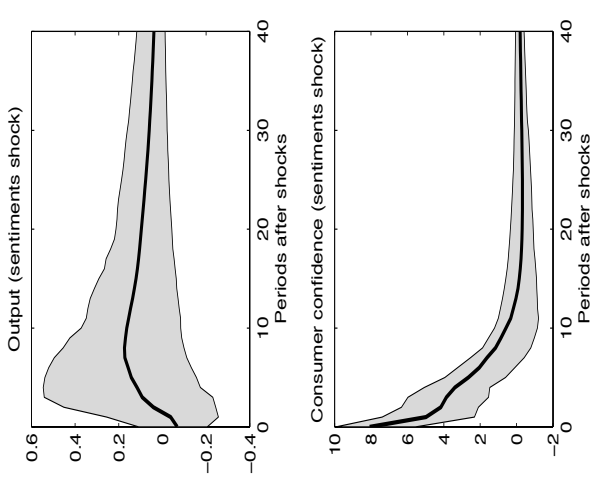

卷宁

密

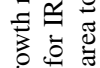

o. 흔

要

可

帚它

迈

过

국

으용

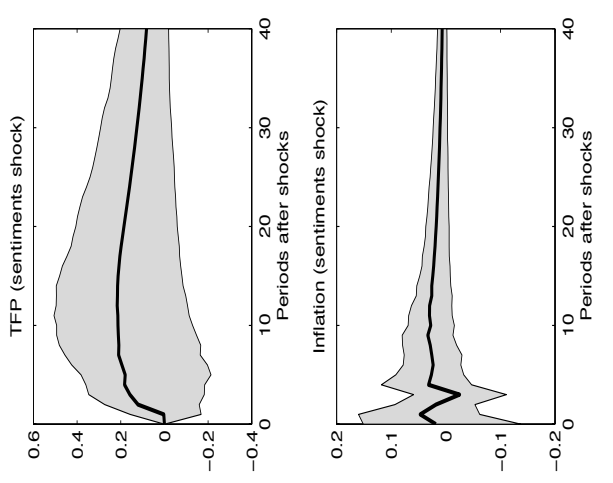

呅

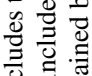

竞

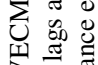

递

ํ.

运

혼

医

읠

笠站 
Figure 9: News Shock in the Benchmark VECM Model and in the Factor Augmented VECM

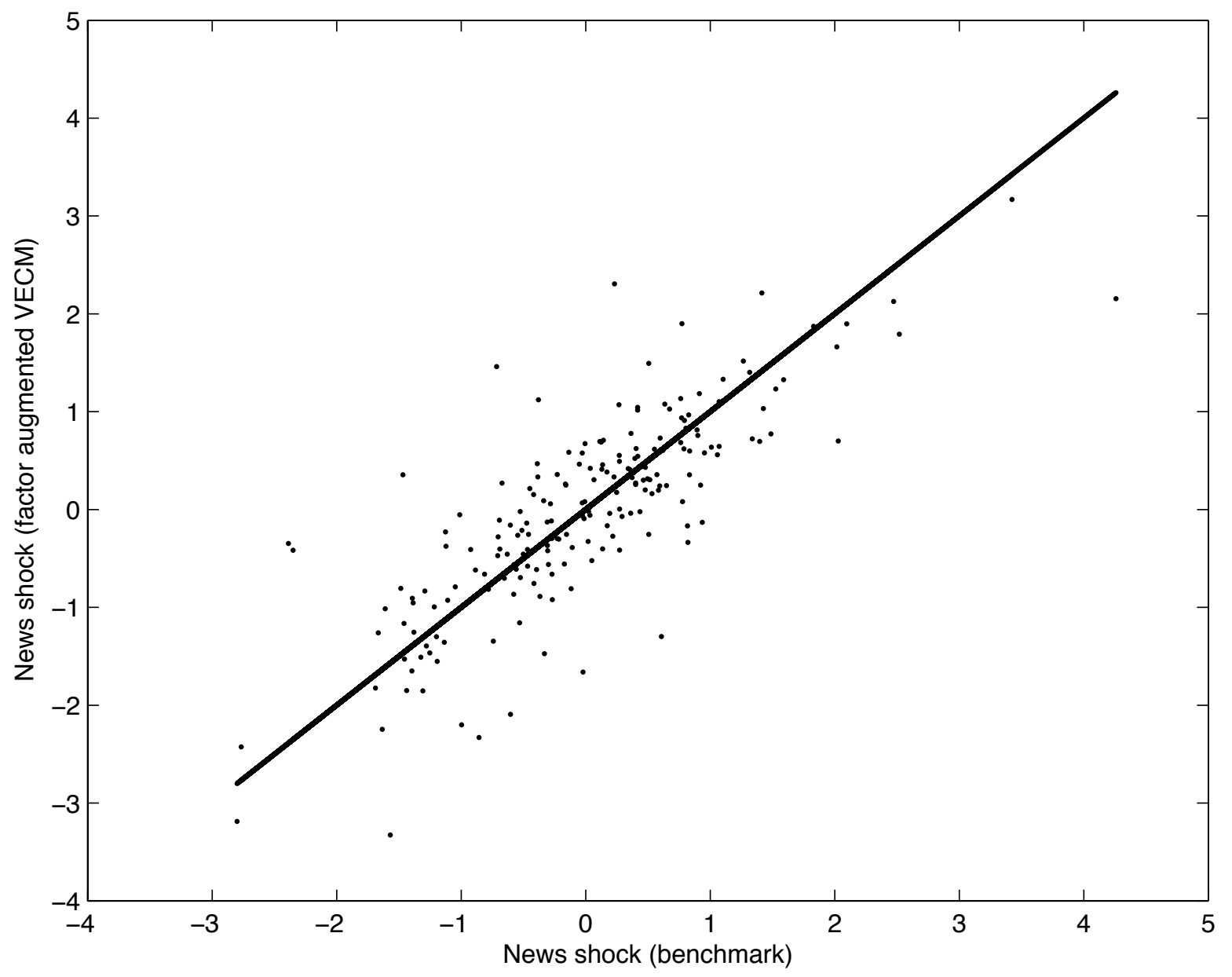

Note: The benchmark VECM includes the growth rate of adjusted TFP, the growth rate of real per capita GDP, the rate of inflation (CPI all) and the measure E5Y of consumer confidence. The Factor Augmented VECM includes the growth rate of adjusted TFP, the growth rate of real per capita GDP, the rate of inflation (CPI all), the factor and the measure E5Y of consumer confidence. The sample period is 1960:1-2011:4. Three lags are included in the VECMs. 
Figure 10: Variance Decomposition (SVECM \& Investment)
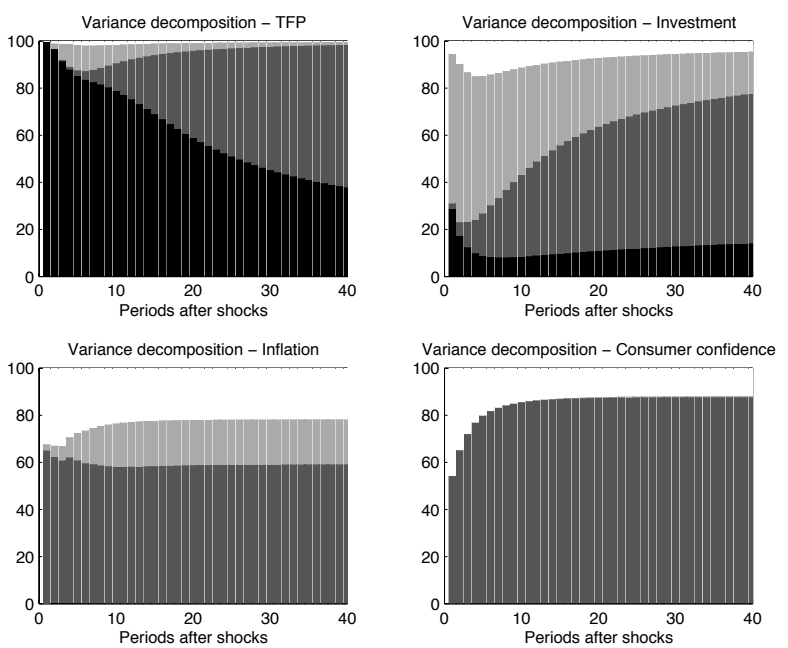

Note: The VECM includes the growth rate of adjusted TFP, the growth rate of real per capita investment, the rate of inflation (CPI all) and the measure E5Y of consumer confidence. The sample period is 1960:1-2011:4. Three lags are included in the VECM. The selected horizon for IRFs is 40. The white area corresponds to the share of variance explained by the sentiments shock, the light grey area to the demand shock, the dark grey area to the news shock on TFP and the dark area to the surprise shock on TFP.

Figure 11: Variance Decomposition (SVECM \& Consumption)
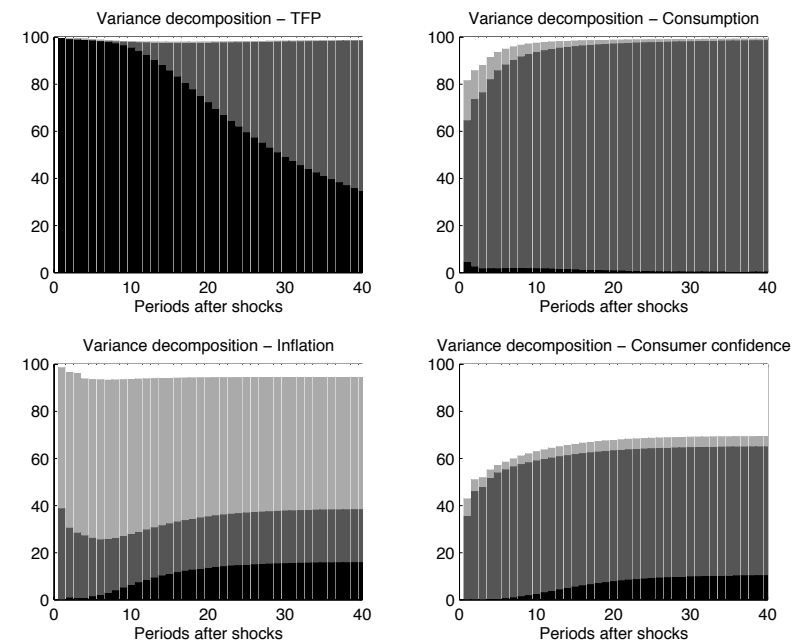

Note: The VECM includes the growth rate of adjusted TFP, the growth rate of real per capita consumption (nondurable \& service), the rate of inflation (CPI all) and the measure E5Y of consumer confidence. The sample period is 1960:1-2011:4. Three lags are included in the VECM. The selected horizon for IRFs is 40. The white area corresponds to the share of variance explained by the sentiments shock, the light grey area to the demand shock, the dark grey area to the news shock on TFP and the dark area to the surprise shock on TFP. 
Figure 12: Variance Decomposition (SVECM \& Labor Productivity)
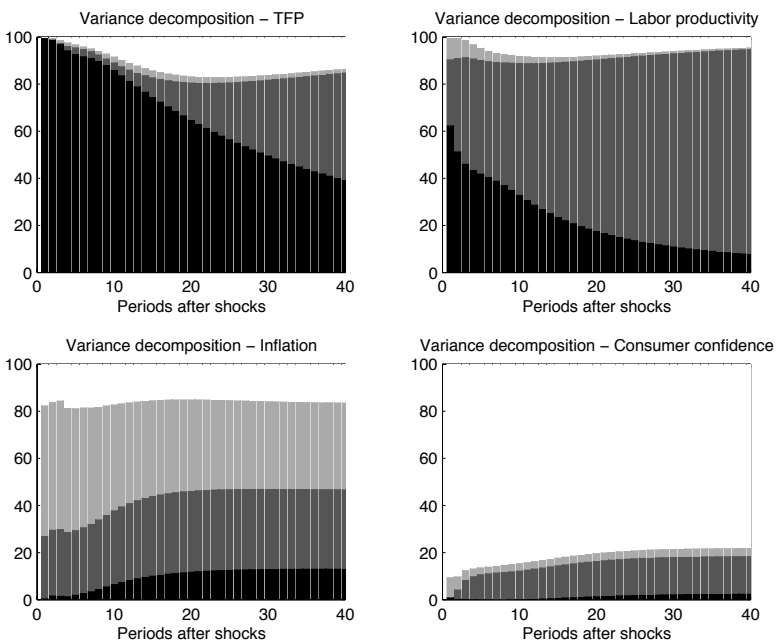

Note: The VECM includes the growth rate of adjusted TFP, the growth rate of labor productivity, the rate of inflation (CPI all) and the measure E5Y of consumer confidence. The sample period is 1960:1-2011:4. Three lags are included in the VECM. The selected horizon for IRFs is 40. The white area corresponds to the share of variance explained by the sentiments shock, the light grey area to the demand shock, the dark grey area to the news shock on TFP and the dark area to the surprise shock on TFP.

Figure 13: Variance Decomposition (SVECM \& Hours Worked)
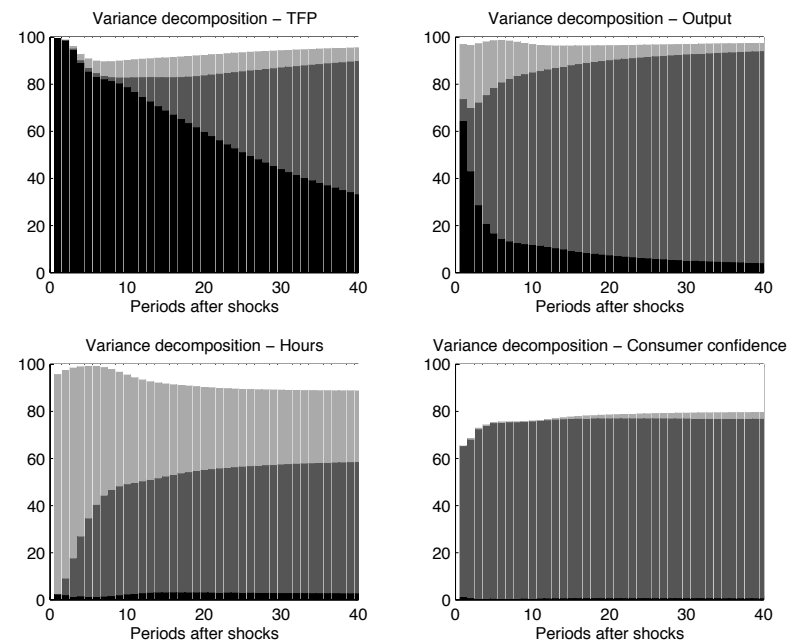

Note: The VECM includes the growth rate of adjusted TFP, the growth rate of real per capita GDP, the (log of) hours worked and the measure E5Y of consumer confidence. The sample period is 1960:1-2011:4. Three lags are included in the VECM. The selected horizon for IRFs is 40. The white area corresponds to the share of variance explained by the sentiments shock, the light grey area to the labor market shock, the dark grey area to the news shock on TFP and the dark area to the surprise shock on TFP. 
Figure 14: Variance Decomposition (Barsky-Sims Identification)
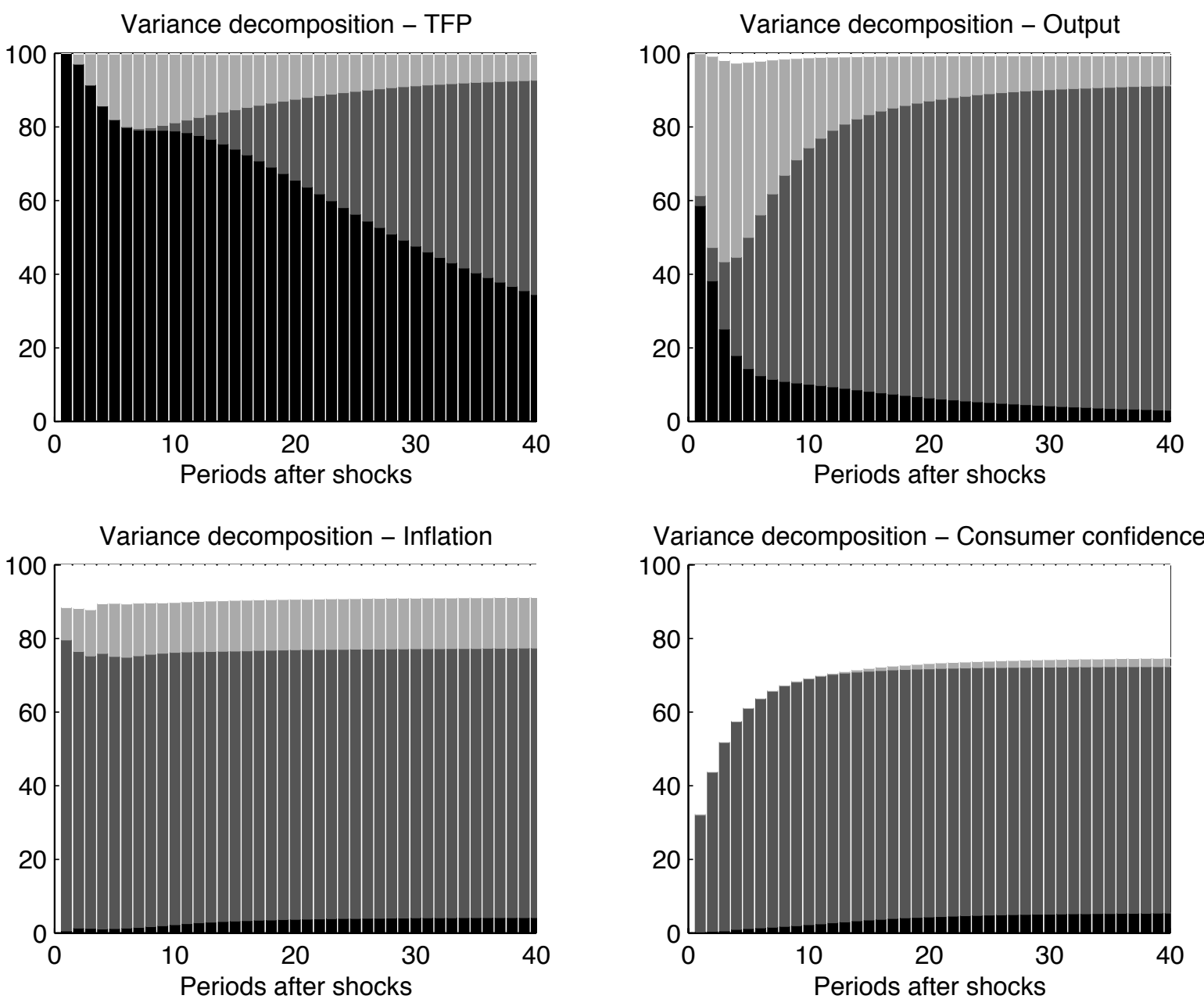

Note: The VECM includes the growth rate of adjusted TFP, the growth rate of real per capita GDP, the rate of inflation (CPI all) and the measure E5Y of consumer confidence. The sample period is 1960:1-2011:4. Three lags are included in the VECM. The selected horizon for IRFs is 40 . The white area corresponds to the share of variance explained by the sentiments shock, the light grey area to the demand shock, the dark grey area to the news shock on TFP and the dark area to the surprise shock on TFP. 
Figure 15: Robustness Analysis - Variance Decomposition

CPI Less Food and Energy
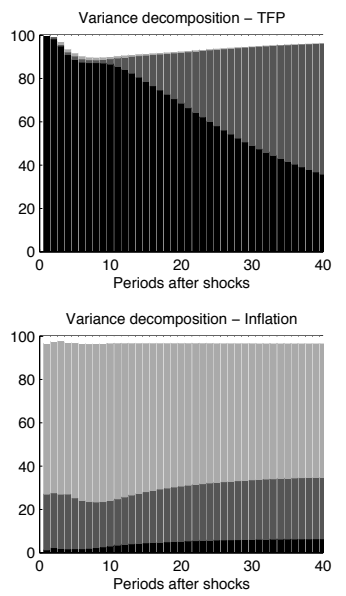

SVECM with ICS
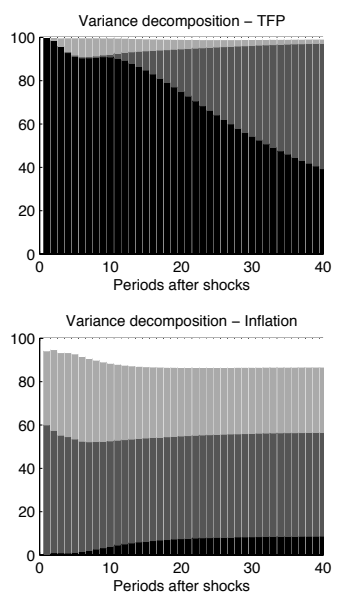
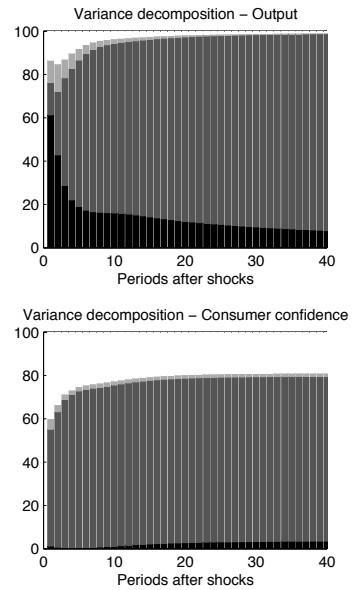

SVECM with E12M

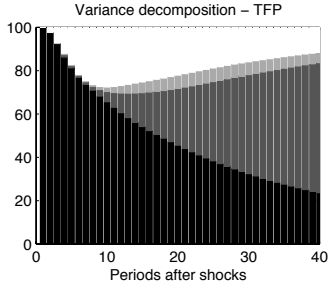

Variance decomposition - Inflation

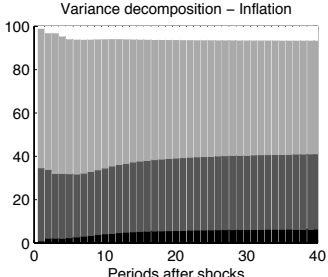

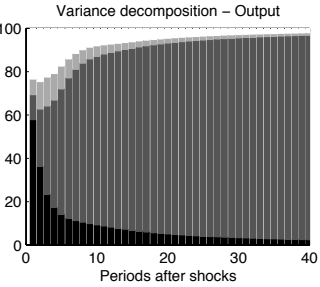

ariance decomposition - Consumer confidence

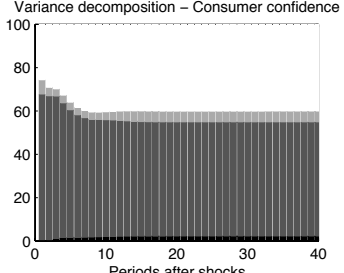

SVECM with Business Confidence
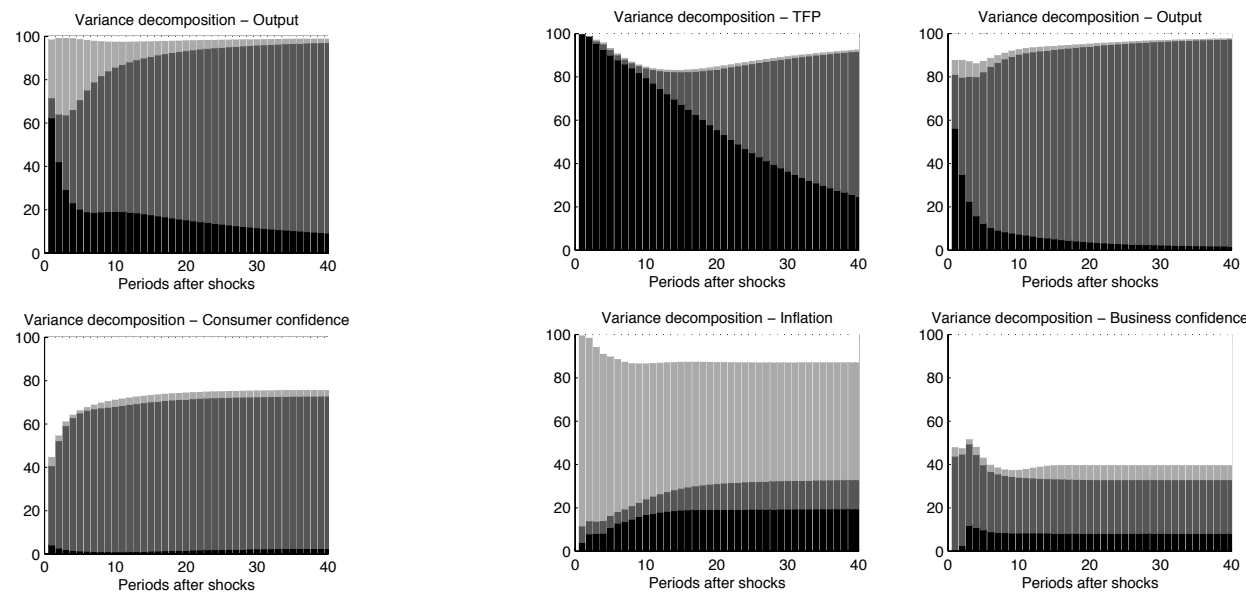

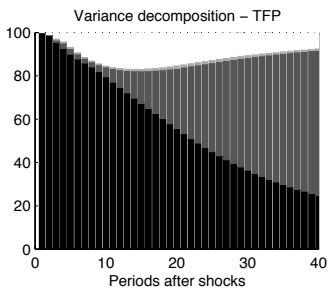

Variance decomposition - Inflation
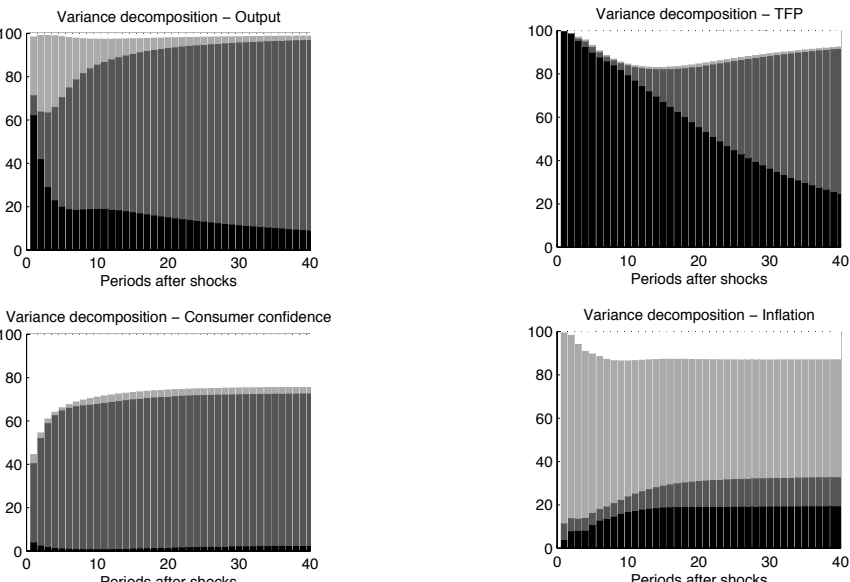

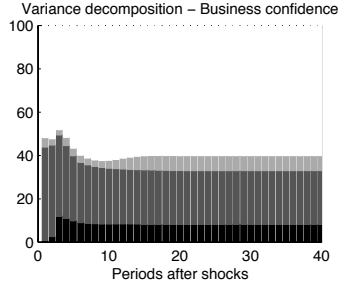

Note: The VECM includes the growth rate of adjusted TFP, the growth rate of real per capita GDP, the rate of inflation (CPI all or CPI less) and different measures of (consumer or CEO) confidence. The sample period is 1960:1-2011:4. Three lags are included in the VECM. The selected horizon for IRFs is 40. The white area corresponds to the share of variance explained by the sentiments shock, the light grey area to the demand shock, the dark grey area to the news shock on TFP and the dark area to the surprise shock on TFP. 